\title{
III. DIE FRANZÖSISCHE POLITIK IN DEN TROIS-ÉVÊCHÉS VON 1552 BIS 1633
}

\section{Vertrag von Chambord und »Voyage de l'Allemagne«}

Die französische Lothringenpolitik in der frühen Neuzeit basierte auf zwei Säulen: zum einen auf der seit dem Mittelalter feststellbaren grundsätzlichen Tendenz zur Ausweitung der Krondomäne ${ }^{1}$, zum anderen auf dem Gegensatz zwischen dem französischen Königshaus und Habsburg ${ }^{2}$, der sich insbesondere nach den Italienkriegen in der ersten Hälfte des 16. Jahrhunderts herausbildete. Während die Frage der königlichen Rechte erst in der zweiten Hälfte des 16. und im 17. Jahrhundert im Vordergrund der französischen Politik stehen sollte, hatte der französisch-habsburgische Konflikt im Vorfeld der Ereignisse von 1552 die an strategischen Schlüsselpositionen gelegenen Trois-Évêchés ins Blickfeld der europäischen Politik gerückt.

Bereits seit dem Mittelalter war von französischer Seite ein zunehmendes Interesse an Metz, Toul und Verdun zu beobachten, das sich in Handelsvereinbarungen, Schutzverträgen und Bemühungen um eine Besetzung der Bischofsstühle mit Sympathisanten der französischen Krone manifestierte ${ }^{3}$. Im Zusammenhang mit diesem Interesse ist auch der Abschluß des Vertrages von Chambord zu sehen: Die zunehmende Annäherung des französischen Königs Heinrich II. an die protestantischen Reichsfürsten hatte $1551 \mathrm{zu}$ einem Offensivbündnis geführt, das in diesem Vertrag im Jahr 1552 seine endgültige Form fand $^{4}$. Als Gegenleistung für die militärische und finanzielle Unterstützung der protestantischen Reichsfürsten bestätigte der Vertrag, daß diese es [...] vor guet erachtet[en], daß Heinrich II. Cambrai, Metz, Toul, Verdun und was derselben mehr werden besetzte und als Vicarius inhabe und behalte ${ }^{5}$.

'MIECK, Entstehung, S. 26. Auf diese Thematik wird im achten Kapitel näher eingegangen.

${ }^{2}$ Zum Verhältnis Frankreichs zum Reich und den Fürsten vgl. Gaston ZELLER, La France et l'Allemagne depuis dix siècles, Paris 1932, S. 86-97.

${ }^{3}$ Zur Vorgeschichte von 1552 vgl. für Metz: ZELLER, Réunion, Bd. 1; für Verdun: AIMOND, Relations; für Toul: PIMODAN, Réunion, S. 1-14; eine kurze Zusammenstellung der älteren Schutzverträge bei STEIN, Protection Royale, S. 19-22.

${ }^{4} \mathrm{Zu}$ den Verhandlungen im Herbst 1551 und Januar 1552 vgl. RABE, Deutsche Geschichte $1500-1600$, S. $433 f$.

${ }^{5}$ Der Vertrag von Chambord ist abgedruckt bei DiCKMANN, Geschichte in Quellen, Bd. 3, S. 197-199. „Vicarius« war eigentlich der Titel eines kaiserlichen Statthalters in den fremd- 
Interessant ist hierbei, daß die Frage der lothringischen Städte nicht vom französischen König, sondern von den Reichsfürsten aufgebracht wurde, die mit diesem Schritt offenbar die kaiserlichen Verbindungen vom Oberrhein in die Niederlande kappen wollten ${ }^{6}$. Heinrich II. nahm die Gelegenheit jedoch wahr und begann umgehend mit Rüstungen: Schon am 13. März 1552 marschierten die französischen Truppen kampflos in Toul ein ${ }^{7}$. Einen Tag später öffnete ihnen die Hauptstadt des Herzogtums Lothringen, Nancy, die Tore. Der junge Herzog wurde der Vormundschaft seiner Mutter entzogen und an den französischen Königshof gebracht ${ }^{8}$. Auch in Metz wurde dem König keinerlei Widerstand entgegengesetzt: Mit einem prunkvollen Einzug in die Stadt feierte Heinrich II. seinen kampflosen Sieg. Wie bereits in Toul ließ er auch hier eine Garnison in der Stadt ${ }^{9}$. Der danach ursprünglich geplante Weiterzug an den Rhein wurde wegen der Aufnahme von Verhandlungen der protestantischen Reichsfürsten mit dem Bruder des Kaisers abgebrochen. In einer Schleife wandte sich Heinrich II. wieder nach Westen und hielt am 12. Juni 1552 auch in Verdun feierlichen Einzug ${ }^{10}$. Der französische König kontrollierte somit innerhalb weniger Monate alle wichtigen Städte im lothringischen Raum ${ }^{11}$. Er hatte nicht den geringsten Widerstand angetroffen. Kaiser Karl V. reagierte erst relativ spät und versuchte im Herbst 1552, Metz zurückzuerobern. Er scheiterte nach drei Monaten schließlich an der Verteidigung durch die Franzosen und an Nachschub- und Gesundheitsproblemen in der eigenen Armee ${ }^{12}$. Die Bischofsstädte blieben in französischer Hand.

Vor allem in Metz und in Verdun hatte die Ankunft der französischen Truppen innerstädtische Konflikte verstärkt und das Kräfteverhältnis dauerhaft beeinflußt. In Metz hatte der Bischof Robert de Lenoncourt ${ }^{13}$ schon bei seinem Amtsantritt im Jahr 1550 durch eine feierliche Einzugszeremonie seine Absichten zur Stärkung der bischöflichen Position in der Stadt Metz deutlich ge-

sprachigen Gebieten des Reiches, z.B. in Italien - die protestantischen Reichsfürsten waren nicht berechtigt, Heinrich II. diesen Titel zuzusprechen.

${ }^{6}$ Eine Bewertung dieser Vorgänge, die dem Vorgehen Heinrichs II. jede Expansionsidee an den Rhein abspricht, bei ZELLER, La France et l'Allemagne, S. $96 \mathrm{f}$.

${ }^{7}$ CABourdin, Histoire de la Lorraine, Bd. 3,1, S. 69f.

${ }^{8}$ Ibid. S. 70.

${ }^{9}$ BOUR, Histoire de Metz, S. 98.

${ }^{10}$ CABOURDIN, Histoire de la Lorraine, Bd. 3,1, S. 72.

${ }^{11}$ Vgl. die Karte ibid. S. 69.

${ }^{12}$ Vgl. Jean RiGaULT (Hg.), Chanson sur le siège de Metz par Charles-Quint, in: Annales de l'Est 3 (1952) S. 304-306, sowie Karl BRANDI, Kaiser Karl V. Werden und Wirklichkeit einer Persönlichkeit und eines Weltreiches, München 1937, und Ferdinand SEIBT, Karl V. Der Kaiser und die Reformation, Berlin 1990, S. 190.

${ }^{13}$ Er gehörte zur Klientel des lothringischen Herzogshauses und hatte schon vor Amtsantritt große Sympathien für Frankreich gezeigt, vgl. CABOURDIN, Histoire de la Lorraine, Bd. 3,1, S. 66. 
macht $^{14}$. Auch hatte er versucht, die Generalstände des Hochstifts in Metz selbst einberufen zu lassen ${ }^{15}$, und sich von Beginn seiner Amtszeit an in innerstädtische Machtkämpfe eingemischt ${ }^{16}$. Nach der gescheiterten kaiserlichen Belagerung profitierte der Metzer Bischof nun von der Protektion des französischen Gouverneurs und der Flucht der herzogs- und kaisertreuen städtischen Führungsschicht, die sich auf ihre Landsitze in der Umgebung zurückgezogen hatte. Unter Umgehung der seit dem 13. Jahrhundert üblichen Kooptation ließ der Bischof nach hochmittelalterlichem Brauch die städtischen Funktionsträger in den Pfarreien nun direkt wählen, wobei er sich unter den Gewählten die Auswahl und Ernennung des Rates der Dreizehn selbst vorbehielt ${ }^{17}$. Diese Maßnahme sicherte ihm die Unterstützung breiter Bevölkerungsschichten, die bisher ohne jede Beteiligung an der Stadtregierung waren. Gleichzeitig verband Bischof Robert de Lenoncourt damit einen persönlichen Treueid aller Amtsträger. Er war wieder zum eigentlichen Stadtherrn von Metz geworden.

Ganz ähnlich verliefen die Ereignisse in Verdun: Die inneren Konflikte zwischen der patrizischen Führungsschicht und den übrigen Bürgern, zwischen Magistrat, Klerus und Bischof waren ganz ähnlich wie in Metz ${ }^{18}$. Zudem hatte der französische König in Verdun bereits in den Jahren vor der Besetzung sehr geschickt agiert, indem er den Handel zwischen der Stadt und seinem Königreich erleichterte und sich ansonsten zurückhielt, während Kaiser Karl V. die ohnehin wirtschaftlich schwer angeschlagene Stadt mit immer neuen Steuerforderungen zu belasteten versuchte ${ }^{19}$. Auch in Verdun hatte der französische König in der Person des Bischofs Nicolas Psaume und in Kardinal Charles de Lorraine-Guise, der als Verwalter der weltlichen Belange der Hochstifte Metz und Verdun der eigentliche Territorialherr über die bischöflichen Besitzungen war, Parteigänger vor Ort. Kardinal Charles de Lorraine-Guise nutzte entsprechend gleich die Gelegenheit und legte nur drei Tage nach der feierlichen Begrüßung des französischen Königs in der Stadt eine Verordnung ${ }^{20}$ vor, mit der der bischofsfeindliche Stadtrat entmachtet wurde. Gleichzeitig wurden sechs

\footnotetext{
${ }^{14}$ Diese Zeremonie hatte man in Metz zum letzten Mal im Jahr 1484 gesehen, vgl. ZELLER, Réunion, Bd. 1, S. 285.

${ }^{15}$ Vgl. CABOURDIN, Histoire de la Lorraine, Bd. 3,1, S. 67.

${ }^{16}$ Die komplizierte Situation in Metz, in der auch konfessionelle Konflikte eine wichtige Rolle spielten, kann hier nur ansatzweise geschildert werden, vgl. dazu die ausführliche und kenntnisreiche Darstellung bei ZELLER, Réunion, Bd. 1, Kap. 3.

${ }^{17}$ ZELLER, Réunion, Bd. 2, S. 1-6; CABOURDIN, Histoire de la Lorraine, Bd. 3,1, S. 81.

${ }^{18}$ Anders als in Metz fehlte jedoch die konfessionelle Komponente des Konfliktes. Auch hier können die Ereignisse nur sehr verkürzt dargestellt werden, vgl. SCHNEIDER, Cité de Verdun, S. 327-348.

${ }^{19}$ CABourdin, Histoire de la Lorraine, Bd. 3,1, S. 66.

${ }^{20}$ A.C. Verdun CC 2, gedruckt bei Nicolas Ursin FRIZON (Hg.), Petite bibliothèque verdunnoise. Recueil des documents inédits et des pièces rares sur Verdun et le pays verdunnois, 4 Bde., Verdun 1885-1888, hier Bd. 1, S. 171-182.
} 
bedeutende Vertreter der Patrizierfamilien wegen Unterschlagungen angeklagt $^{21}$. Damit war das wichtigste Organ der patrizischen Stadtregierung praktisch entmachtet, und der Bischof auch in Verdun wieder die mächtigste Kraft in der Stadt. Die städtischen Ämter wurden genau wie in Metz nun nicht mehr durch Kooptation der Patrizier, sondern vom Bischof (bzw. seinem weltlichen Verwalter) auf Nominierung der einzelnen Pfarreibewohner vergeben. Geschickt hatte Kardinal Charles de Lorraine-Guise hierbei die bisher von der Stadtregierung ausgeschlossene Bevölkerung auf seine Seite gebracht - auch hier sind Parallelen zu Metz unverkennbar ${ }^{22}$.

In Toul war das Verhältnis zwischen Bischof, Stadtbürgern und Domkapitel in den Jahren vor 1552 ebenfalls keineswegs unproblematisch. Zwar hatte der Bischof in Toul grundsätzlich eine wesentlich stärkere Stellung als in den beiden anderen Städten, doch faktisch war seine Macht vor allem durch das Domkapitel stark begrenzt ${ }^{23}$. Unter Bischof Toussaint d'Hocedy hatte sich das Konfliktpotential erstmals bei seinem Amtsantritt im Jahr 1543 gezeigt, wo dem neuen Kirchenoberhaupt weder von der Bürgerschaft noch vom Domkapitel der ubliche festliche Empfang bereitet worden war. Auch in den folgenden Jahren konnte sich Toussaint d'Hocedy, der selbst weder aus dem lothringischen Herzogshaus noch aus einer anderen Familie des regionalen Hochadels stammte, kaum durchsetzen ${ }^{24}$. Der Kaiser hatte durch hohe Steuerforderungen und Eingriffe in die Besetzung der Domkapitel ähnlich wie in Verdun zahlreiche Sympathien bei der Stadtbevölkerung wie der Geistlichkeit verloren $^{25}$. So war der Boden auf zweierlei Art bereitet: Der Bischof erhoffte sich mit französischer Hilfe mehr Autorität, die Stadtbürger und das Domkapitel erhofften sich Freiheit von kaiserlicher Einmischung und den Steuerforderungen des Reiches. So verwundert es kaum, daß die französischen Truppen von den Stadtbürgern mit Jubel empfangen wurden ${ }^{26}$. Große Veränderungen traten jedoch zunächst nicht ein. Der Touler Bischof verhielt sich abwartend und der vom französischen König eingesetzte Gouverneur, der im Gegensatz zu seinen Kollegen in den beiden anderen Städten nicht dem Bischof das Feld überließ, stieß sehr schnell auf Widerstände. Sein Befehl an die Stadtbürger, alle Waffen abzuliefern, wurde ebenso ignoriert wie seine Bemühungen um eine Verstärkung der Stadtmauer ${ }^{27}$. Zudem geriet er in Konflikt mit dem alten

${ }^{21}$ LE MOIGNE, in: GIRARDET (Hg.), Histoire de Verdun, S. 131.

${ }^{22}$ Zur Bewertung vgl. KIEFFER, Verdun, S. 23.

${ }^{23}$ CABourdin, Terres et hommes, Bd. 1, S. 12.

${ }^{24}$ Pimodan, Réunion, S. 1-7.

${ }^{25}$ Ibid. S. 9-13.

${ }^{26}$ Ibid. S. 15.

${ }^{27}$ CABOURdIN, Histoire de la Lorraine, Bd. 3,1, S. 82. 
und angesehenen Schöffenmeister Jean Boileau, der sich demonstrativ aus der Stadt zurückzog, als der Gouverneur die Stadtschlüssel an sich nahm ${ }^{28}$.

Die vom französischen König in allen drei Städten eingesetzten Garnisonen hatten eine eigene Rechtsorganisation, die sie zu völlig von der Bürgergemeinde getrennten Körperschaften machte. Insbesondere im Bereich der Strafverfolgung führte dieser Punkt schon bald zu Schwierigkeiten. Die Rechtsprechung für die französischen Soldaten oblag den prévôts des maréchaux, also Angehörigen der Armee selbst. Kein Militärangehöriger durfte vor ein reguläres Gericht geladen werden, alle Verfahren, auch wenn Zivilpersonen als Kläger fungierten, wurden vor dem Militärgericht entschieden.

In Metz zeigten sich die Probleme, die die Anwendung der französischen Militärjustiz auf die Besatzungssoldaten mit sich brachte, zuerst: Der dort ansässige prévôt des maréchaux geriet schnell in den Ruf der Parteilichkeit und hatte sich bei der Stadtbevölkerung schon seit der Belagerung unbeliebt gemacht. Als er einem zum Galgen verurteilten Straftäter 1553 bei der Flucht half, mußte der Gouverneur reagieren und entließ ihn $^{29}$.

Zum gleichen Zeitpunkt befand sich Charles de Marillac, Bischof von Vannes, in diplomatischer Mission des französischen Königs in der Moselstadt (er sollte dort sächsische Abgesandte treffen). Sein zweiter Auftrag war, dem König einen Bericht über die Gerichtsbarkeit in Metz anzufertigen ${ }^{30}$. Marillac ersetzte vorläufig den abgesetzten prévôt des maréchaux und konnte so aus der Praxis berichten.

Marillacs Mission zeigt, daß schon in den ersten Jahren nach 1552 die Justiz im Zentrum der königlichen Bemühungen stand. Sein Interesse an den städtischen Institutionen wurde vom Metzer Bischof de Lenoncourt jedoch mit Hinweis auf die umfassenden Rechte des Bischofs brüsk zurückgewiesen. Der Gesandte mußte also neben den Problemen mit der Militärgerichtsbarkeit auch besorgt nach Paris melden, der Metzer Bischof habe sich seine allmächtige Position nicht zur Stärkung der königlichen, sondern der eigenen Autorität angeeignet $^{31}$. Marillac legte nahe, jemanden nach Metz zu schicken, wum die Gerichtsbarkeit auszuüben und neu zu regeln, da es dringend bedarf und nötig ist, daß der König seine Hand darüber hält und seine Autorität benutzt « ${ }^{32}$.

\footnotetext{
${ }^{28}$ Jean du PASQUiER, Mémoires, hg. v. DAULnOY, PILLEMENT, S. $24 f$.

${ }^{29}$ ZELLER, Réunion, Bd. 2, S. $145 \mathrm{f}$.

${ }^{30}$ Ibid. S. 6 f.

${ }^{31}$ Ibid.

${ }^{32}$ Übersetzung der Autorin. Der gesamte Briefwechsel von Marillac mit dem König und dem Konnetabel Montmorency findet sich als zeitgenössische Kopie in der BnF, fr. 3100, hier fol. 43: et relève d'aultant de poyne celuy qui viendra après pour exercer et regler la justice, comme il est très requis et nécessaire que le Roy mecte la main et use de son aucthorité.
} 
Wahrscheinlich als Reaktion auf diesen Rapport wurde François de Laubespine im Frühjahr 1554 als président de la justice à Metz et pays Messin emannt und an die Mosel gesandt ${ }^{33}$.

\section{Zwischen Militär und Zivilverwaltung: Der président von Metz}

Mit dem Amt des président de la justice in Metz wurde eine zuvor in Frankreich eigentlich unbekannte Position geschaffen ${ }^{34}$. In der Begrifflichkeit wird jedoch die Nähe zu den fast gleichzeitig etablierten Gerichten der présidiaux deutlich. Genau wie diese sollte der Metzer président die Aufsicht über die Militärjustiz führen. Auch die den Présidiaux-Gerichten zukommende Berufungsgerichtsbarkeit in Zivilsachen sollte vom président in Zukunft immer wieder beansprucht werden ${ }^{35}$. Allerdings wurde in Metz kein ganzes Gericht geschaffen, sondern lediglich eine Person mit den entsprechenden Kompetenzen ausgestattet. Der erste Amtsinhaber, François de Laubespine, hatte zuvor als maître des requêtes, das heißt als Richter am königlichen Hofgericht, nicht nur Erfahrung in der Schlichtung von Konflikten gesammelt, sondern durch die Bearbeitung von requêtes, also Gesuchen, Eingaben und Suppliken, auch ein Gespür für die Stimmung in der Bevölkerung erhalten ${ }^{36}$. Zudem galt er als sehr tolerant gegenüber Protestanten, vielleicht war er sogar selbst Protestant ${ }^{37}$ - ein wichtiges Kriterium in einer Stadt wie Metz, in der Protestanten zu diesem Zeitpunkt ein Drittel der Bevölkerung ausmachten und die Hälfte aller wichtigen Amtsträger stellten ${ }^{38}$.

$\mathrm{Daß}$ ein maitre des requêtes außerhalb von Paris tätig wurde, war hierbei nicht ungewöhnlich. Inspektionsreisen (chevauchées genannt) waren fester Bestandteil des Amtes. In einem Edikt von Heinrich II. (vom August 1553)

\footnotetext{
${ }^{33}$ So bei CABOURDiN, Histoire de la Lorraine, Bd. 3,1, S. 82.

${ }^{34} \mathrm{Er}$ ist nicht zu verwechseln mit dem Vorsitzenden eines Présidial-Gerichtes im Königreich. Dazu auch ZELLER, Réunion, Bd. 2, S. 146.

${ }^{35} \mathrm{Zu}$ den Présidial-Gerichten vgl. die Ausführungen zum französischen Gerichtswesen in Christine PETRY, »Les grands mangent les petits«. Zur Organisation der Strafgerichtsbarkeit im Frankreich des 16, und 17. Jahrhunderts, in: Harriet RUDOLPH, Helga SCHNABELSCHÜLE (Hg.), Justiz=Justice=Justicia? Rahmenbedingungen von Strafjustiz im frühneuzeitlichen Europa, Trier 2003 (Trierer Historische Forschungen, 48), S. 179-196.

${ }^{36} \mathrm{Zu}$ Aufgaben und Stellung der maîtres des requêtes vgl. LEBIGRE, Justice du Roi, S. 51-53.

${ }^{37}$ ZELLER, Réunion, Bd. 2, S. 147.

${ }^{38} \mathrm{Vgl}$. Gérard MichaUX, Réforme catholique et Contre-Réforme à Metz au XVII siècle, in: François-Yves Le MoIGNe, Gérard MiChauX (Hg.), Protestants Messins et mosellans XVI'XX' siècles, Metz 1988, S. 47-70, hier S. 47.
} 
sind die Aufgaben bei solchen Reisen genau beschrieben: die maitres des requêtes sollten die örtlichen Justizbeamten kontrollieren, mögliche Beschwerden gegen diese entgegennehmen, das Verhalten der Militärs gegenüber der Zivilbevölkerung und die Verfahren der Militärrichter überwachen, die korrekte Verwaltung der städtischen Finanzen und die gerechte Verteilung der Steuerlast sicherstellen, sowie Religionsabweichungen in der entsprechenden Stadt nach Paris berichten. Allerdings hatten die maittres des requêtes bei diesen Inspektionsreisen keinerlei Entscheidungskompetenzen, sondern lediglich eine Überwachungsfunktion ${ }^{39}$. Auch in diesem Zusammenhang ließ sich Laubespines Ernennung also in eine Tradition einordnen, jedoch mit dem Unterschied, daß das Amt des président in Metz auf Dauer angelegt war.

Laubespines Funktion oszillierte also zunächst zwischen den dargestellten Funktionen eines Présidial-Gerichts und einer Inspektionsreise. Kurz nach seiner Ankunft in Metz wurde 1555 öfentlich eine Ordonnanz verlesen, die seine Aufgaben präzisierte. Diese Ordonnanz, angeblich vom Magistrat der Stadt erlassen, tatsächlich jedoch eher aus der Feder Laubespines ${ }^{40}$, betonte vor allem die Überwachungs- und Ermittlungsfunktion und etablierte den président als erste Anlaufstelle für jeden qui se veule plaindre ou demander quelque chose... sans forme ny figure de procès. Der président agierte hierbei nicht allein, sondern gemeinsam mit dem Schöffenmeister, dessen Rat und den Dreizehn $^{41}$. Erst wenn das Verfahren vor diesem Komitee nicht geschlichtet, oder das Anliegen oder die Beschwerde nicht sogleich bearbeitet werden konnte, wurden die Kläger an die ordentlichen Gerichte weiter verwiesen. Insbesondere bei Verfahren zwischen Militärangehörigen und Stadtbürgern und bei Prozessen, die seit langer Zeit vor dem Reichskammergericht anhängig und festgefahren waren, war diese Schlichtungsinstanz, die »ohne Form und Gestalt eines [regulären] Gerichtsprozesses« und damit auch ohne Gesichtsverlust eine Einigung der Parteien ermöglichte, eine attraktive Alternative ${ }^{42}$.

$\mathrm{Da} B$ der président beständig versuchte, seinen relativ eng umgrenzten Aufgabenbereich auszuweiten, ist bereits für die Amtszeit François de Laubespines zu vermuten ${ }^{43}$. Für seinen 1558 ernannten Nachfolger Antoine Senneton

\footnotetext{
${ }^{39}$ MOUSNIER, Institutions, Bd. 2, S. 484f.

${ }^{40}$ In späteren remontrances des Magistrats wurde betont, daß die Ordonnanz von 1555 auf Aufforderung des président entstanden sei, vgl. ZELLER, Réunion, Bd. 2, S. 150.

${ }^{41}$ BnF, N.a.fr. 4831 (Abschrift Prost) - eine etwas andere Deutung bei ZELLER, Réunion, Bd. 2, S. 150f.

${ }^{42}$ Leider sind insbesondere aus den ersten Jahren nur sehr wenige Verfahren, die vor dem président geführt wurden, erhalten. Vgl. die Aufzählung und ihre Bewertung bei ZELLER, ibid. S. $148 \mathrm{f}$.

${ }^{43}$ So ZELLER, ibid. S. 152 (Anm.). Zeller konnte hierfür auf eine heute verlorene requête der Bürger von Metz zurückgreifen, in denen sie sich über diese Ausweitungsversuche beschweren.
} 
wurde dann bereits im Ernennungsbrief ausdruicklich die Kompetenz, Recht zu sprechen, hinzugefügt. Der président sollte danach souverän, d.h. ohne Berufung, über alle Delikte entscheiden, die von Untertanen des Königs begangen wurden, sowie in allen Rechtsfragen, in denen Untertanen des Königs eine der Prozeßparteien stellten ${ }^{44}$. Damit trat die Gerichtsbarkeit des président faktisch in Konkurrenz zu einer zweiten königlichen Instanz vor Ort, dem prévôt des maréchaux ${ }^{45}$. Es scheint jedoch, daß die Kompetenzen zwischen prévôt und président in Metz schon bald deutlich aufgeteilt wurden: Eine königliche Ordonnanz von 1569 trennte die Rechtsfragen zwischen zwei Militärangehörigen (sie wurden vom prévôt des maréchaux entschieden) von solchen, in denen Bürger von Metz und Militärs beteiligt waren (sie wurden vom président entschieden) ${ }^{46}$.

Die sich ohne große Widerstände in Metz etablierende Kompetenz des président als Schlichter in Zivilsachen deutet allerdings darauf, daß dieser insbesondere in der Amtszeit Antoine Sennetons (1558-1568) vor Ort eher als Vertreter der Stadtgemeinde denn als Vertreter des französischen Königs erschien. Diese Tendenz setzte sich auch unter Sennetons Nachfolger Jacques Viart (1568-1606) fort. So wurde Viart, der sich nur selten in Metz aufhielt, am französischen Königshof immer wieder als Fürsprecher der Stadt tätig ${ }^{47}$. Die wenigen überlieferten Urteile legen zudem die Vermutung nahe, daB der président seine Funktion vor allem dazu nutzte, eine Alternative zur Berufung vor dem Reichskammergericht bereitzuhalten ${ }^{48}$. Auf die Berufungen vor dem Reichskammergericht wird an anderer Stelle noch einmal ausfuhrlich einzugehen sein, hier sei jedoch vorweggenommen, daß sich an diesem Punkt die Interessen der Stadt Metz und des französischen Königs durchaus berührten ${ }^{49}$. Problematisch wurde das Verhältnis zwischen président und Stadtgemeinde erst, als das gemeinsame Vorgehen gegen die Berufungen vor dem Reichskammergericht Erfolg zeigte und in den 1570er Jahren sozusagen der »gemeinsame Feind « weggefallen war. Denn nun stellte sich die Frage, wer zukünftig als Berufungsinstanz für das städtische Gericht des Schöffenmeisters fungieren sollte. Während der Magistrat eine souveräne Rechtsprechung beanspruchte, d.h. gar keine Berufung zulassen wollte, war der président bestrebt, seine Gerichtsbarkeit als zweite Instanz durchzusetzen.

Zu einer ersten Machtprobe zwischen Stadt und président kam es 1578 in Metz. Jean Didier, ein Bürger der Stadt, hatte in einer Erbschaftssache beim

\footnotetext{
${ }^{44}$ Sennetons Ernennung findet sich in der BnF, N.a.fr. 7069 und ist abgedruckt bei ZELLER, Réunion, Bd. 2, S. 327.

${ }^{45}$ Zur Funktion der prévôts des maréchaux vgl. LEBIGRE, Justice du Roi, S. 40f.

${ }^{46} \mathrm{BnF}$, Dupuy 335, fol. 79.

${ }^{47}$ ZELLER, Réunion, Bd. 2, S. 161.

48 Ibid. S. 155-158.

${ }^{49}$ Dazu mehr im Kapitel IV.
} 
conseil du roi in Paris Berufung gegen ein städtisches Urteil eingelegt. Doch als der Gerichtsdiener des königlichen Gerichts aus Paris in Metz eintraf, erlitt dieser das gleiche Schicksal wie in den Jahrzehnten zuvor seine Amtskollegen aus Speyer: Der Magistrat der Stadt ließ ihn inhaftieren und schickte dem französischen König ein erzürntes Beschwerdeschreiben ${ }^{50}$. Interessant ist hierbei die Reaktion des Königs. Statt das Verhalten der Metzer Bürger zu kritisieren, entschuldigte er sich für das Vorgehen seines Rates ${ }^{51}$. Als Jean Didier weiter versuchte, seine Rechtsstreitigkeit vor dem conseil du roi zu verfolgen, wandte sich der Metzer Magistrat erneut an den französischen König. Wieder mit Erfolg - dieser erklärte erneut die Annahme des Verfahrens für nichtig und schickte Jean Didier wieder vor die städtischen Gerichte ${ }^{52}$. Doch nun war der président auf den Plan gerufen: Um gegen die Urteile des Schöffenmeisters zumindest eine Möglichkeit der Rechtshilfe zu bieten, schlug er vor, auch in Metz für Kläger die Rechtshilfemöglichkeiten einzuführen, die in Frankreich nach einem letztinstanzlichen Urteil möglich waren, die proposition $d^{\prime}$ 'erreur und die requête civile ${ }^{53}$. Der Vorschlag fand in Metz jedoch nur wenig Anklang. Die Ständevertreter der Stadt nahmen in ihrer Antwort vom 3. September 1580 Jacques Viarts Vorschlag zum Anlaß, die bisher verfolgte Praxis zu verteidigen, in der dem président keine direkten Gerichtsbefugnisse und vor allem nicht die Funktion eines Berufungsrichters für die städtischen Gerichte zustanden ${ }^{54}$. Damit griffen sie jedoch indirekt auch die königliche Bestimmung des Aufgabenbereiches für Viart und seinen Vorgänger Senneton an, die dem président ausdrücklich das Recht einer souveränen, d.h. einem Parlament gleichgesetzten, Gerichtsbarkeit einräumten. Diese Gerichtsbefugnisse waren vor allem auf solche Fälle bezogen, in denen Angehörige der Garnison oder andere französische Untertanen in Rechtsfälle verwickelt waren, doch sie waren vage genug formuliert, um diesen Zuständigkeitsbereich ausdehnen zu können ${ }^{5 s}$. So wurde Viart zusätzlich dazu der Vorsitz im sénat de la justice ordinaire, womit wohl das Gericht des Schöffenmeisters in Metz gemeint war, zugestanden ${ }^{56}$. Auf königlicher Seite sah man in den Äußerungen

\footnotetext{
${ }^{50}$ Nach ZELLER, Réunion, Bd. 2, S. 162: Quelle in A.C. Metz, AA 42, 200-34, Remontrances in A.C. Metz, AA 60, 8-6.

${ }^{11}$ EMMERY, Recueil, Bd. 1, S. 468.

$\$ 2$ Ibid. S. 484.

${ }^{53}$ Beide Prozeduren wurden vor dem conseil du roi entschieden. Während der Kläger in einer proposition d'erreur einen Tatsachenirrtum im Verfahren vermutete, wurden die lettres en forme de requête civile bei nachgewiesenen Formfehlern erstellt. Vgl. dazu LEBIGRE, Justice du Roi, S. $50 f$.

${ }^{54} \mathrm{Vgl}$. die Antwort der drei Stände, gedruckt bei ZELLER, Réunion, Bd. 2, S. 338 (Anhang 16).

${ }^{55}$ Die Ernennung Sennetons ist gedruckt bei ZELLER, ibid. S. 328; die Ernennung Viarts befindet sich in der BnF, Dupuy 335, fol. 79.

${ }^{56}$ Ibid.
} 
der Stände von Metz zu diesem Thema zunehmend eine Gefahr für die französische Autorität, wie an der Reaktion deutlich wird. Die Stände wurden aufgefordert, die gesamten Protokolle in der Sache Didier aus ihren Registern zu entfernen, à ce quelle ne puisse apporter nouvelle occasion de procès et différens entre plusieurs personnes, mesme entre vos concitoyens ${ }^{57}$. Allerdings ohne Erfolg - die Stände verweigerten dem König den Gehorsam ${ }^{58}$ und dieser mußte die Entscheidung zunächst ohne weitere Reaktion hinnehmen. Jean Didiers Rechtsstreit allerdings wurde im Juli 1581 erneut vor dem conseil du roi beraten und man nutzte den Rechtsfall in Paris jetzt dazu, die Gerichtsbarkeit des président durchzusetzen. Den protestierenden Vertretern der Stadtgemeinde wurde nur noch die Wahl zwischen der Anerkennung des conseil $d u$ roi oder der des président gelassen ${ }^{59}$.

Schon einen Monat zuvor hatte der französische König erneut die Befugnisse des président Jacques Viart präzisiert: Seine Urteile sollten denen eines Parlaments entsprechen, »so wie es seit mehr als 28 Jahren schon üblich ist ${ }^{60}$. Doch auch wenn Viart nun in bestimmten Verfahren die Gerichtskompetenz eines Parlaments und damit ein Rang weit über dem des Schöffenmeisters zugesprochen worden war, blieb seine faktische Stellung innerhalb des städtischen Gerichtssystems schwierig. 1585 fiel dem président auf, daß er im Protokoll einer Gerichtssitzung des Schöffenmeisters, an der er teilgenommen hatte, nicht als Vorsitzender, présidant, sondern nur als Teilnehmer assistant aufgeführt wurde. Als er dies anmahnte und eine Neuformulierung forderte in seiner Ernennung war schließlich ausdrücklich bestimmt, daß er présidant im sénat de la justice ordinaire sein könne, wann immer er dies wünsche wichen die Vertreter der Stadtgemeinde mit einer typischen Reaktion aus: Sie baten um die Erlaubnis, zunächst ihre Remonstrationen an den König senden zu dürfen ${ }^{61}$.

Auch die Reaktion des Königs auf diese Remonstration war beispielhaft für den Ablauf solcher Kompetenzkonflikte: Sie war so verschwommen formuliert, daß beide Parteien sie als Bestätigung ihrer Rechte interpretieren konnten. Seinem Vertreter vor Ort schickte der König am gleichen Tage die Instruktion, er solle in allem, was maître-échevin und den Rat der Dreizehn betreffe, so vorsichtig wie möglich, le plus doucement qu'il seroit possible, verfahren $^{62}$. Dieser vorsichtige Kurs gegenüber dem Metzer Magistrat war

${ }^{57}$ Brief des Königs an maître-échevin, Treize und Ständeversammlung vom 20.10.1580, gedruckt bei ZELLER, Réunion, Bd. 2, S. 338f. (Anhang 17).

${ }_{38}$ Antwort der Stände auf einen Brief des Königs vom 23.11.1580, gedruckt bei ZELLER, ibid. S. 339.

${ }^{59}$ Ibid. S. 164 (Urteil des conseil für Didier in A.C. Metz alt 223-3, fol. 24).

${ }^{60}$ Ibid. fol. 5.

${ }^{61}$ Diese Ereignisse bei ZELLER, Réunion, Bd. 2, S. 166f.

${ }^{62}$ Die entscheidenden Partien sind abgedruckt bei ZELLER, ibid. S. 167. 
auch durch die politische Lage im Königreich bedingt: Die Religionskriege banden die Kräfte des französischen Königs und seiner Armee ${ }^{63}$. Toul und Verdun waren zu diesem Zeitpunkt in den Händen der katholischen Liga, und im bikonfessionellen Metz war ein hartes Durchgreifen zu diesem Zeitpunkt unmöglich. Die Frage des Vorranges blieb also vorerst ungeklärt, Jacques Viart verließ - ebenfalls wohl aus politischen Gründen - Metz noch Ende 1585. Er sollte erst 1602 wieder die Stadt betreten ${ }^{64}$.

Nach der französischen Besetzung und den ersten Vorstößen des Gouverneurs in Toul waren dort von königlicher Seite aus keine Eingriffe mehr in die städtische Verwaltung unternommen worden ${ }^{65}$. Selbst der Versuch des Bischofs Toussaint d'Hocedy, seine weltlichen Herrschaftsrechte über das bischöfliche Territorium und die Stadt an den Herzog von Lothringen zu verkaufen ${ }^{66}$, wurde nicht vom französischen König verhindert, sondern durch ein Zusammengehen des Touler Domkapitels und der Bürgerschaft mit dem Kaiser bzw. dem Reichskammergericht und dem Papst ${ }^{67}$. Als das Domkapitel nach dem Tode Toussaint d'Hocedys 1565 zur Neuwahl des Bischofs schritt, griff jedoch der Statthalter des französischen Gouverneurs in Toul ein und untersagte eine Wahl ohne Zustimmung des Königs. Die Frage, ob die Benefizien wie in Frankreich (Vergabe durch den König) oder wie im Reich (Wahl der Domkapitel) zu handhaben seien, war erstmalig aufgeworfen, und damit implizit auch die Frage nach der Rolle des französischen Königs als protecteur oder souverain. Doch noch schien die Zeit für einen Eingriff in die Bischofswahlen nicht reif: Nach der Intervention der lothringischen Herzogin, einer Schwester des Königs, konnte das Domkapitel den von ihm und vom lothringischen Herzogshaus favorisierten Pierre du Châtelet wählen ${ }^{68}$. Der König hingegen bestätigte noch einmal feierlich die Rechte von Klerus, Bürgern und Magistrat ${ }^{69}$.

Wie sein Vorgänger war der neue Touler Bischof Pierre du Châtelet Vorsitzender des herzoglich-lothringischen Staatsrates und nur selten in seiner Stadt

${ }^{63}$ Zur Situation des Königreiches während der Religionskriege und in den Jahren um 1585 vgl. John H. M. SALMON, Society in crisis. France in the sixteenth century, London, Tonbridge 1975, bes. S. 234-241. Eine neue Sicht der Religionskriege bietet Denis CROUZET, Les guerriers de Dieu. La violence au temps des troubles de religion (vers 1525-vers 1610), 2 Bde., Seyssel 1990.

${ }^{64}$ ZELLER, Réunion, Bd. 2, S. 167.

${ }^{65}$ Hiervon ausgenommen ist die Frage des Zusammenlebens der Konfessionen, in die der König und seine Vertreter, auch bedingt durch die zahlreichen Protestanten in der Garnison, immer wieder eingriffen. Vgl. dazu PICARD, Histoire de Toul, S. 643-646 und PIMODAN, Réunion, S. 38-45.

${ }^{66}$ Die Zessionsakte findet sich in BnF, N.a.fr. 7099, fol. 115-118.

${ }^{67}$ Vgl. PICARD, Histoire de Toul, S. 646f.; PIMODAN, Réunion, S. 47-49.

${ }^{68}$ Ibid. S. 67-69.

${ }^{69}$ A.C. Toul AA 2, fol. 99-101. 
anwesend. Er starb 1580. Bei der Wahl seines Nachfolgers nahm der französische König auf subtilere Weise Einfluß: Er schickte einen Brief an das Domkapitel, in dem er dieses bat, seinen Schwager Charles de LorraineVaudemont, der im übrigen auch der Wunschkandidat des lothringischen Herzogs war, zum neuen Bischof zu wählen ${ }^{70}$. Hier zeigt sich, wie stark die Politik Frankreichs gegenüber den Trois-Évêchés stets auch vom Verhältnis zum lothringischen Herzogshaus bestimmt war.

In Verdun hatten sich Bischof Nicolas Psaume und der Kardinal Charles de Lorraine-Guise als Verwalter der weltlichen Belange in den ersten Jahren der Besetzung mit der Neukonstitution der Stadtverfassung von 1552 eine starke Stellung gesichert. 1574 änderte Psaume die Verfassung der Stadt erneut: Nun lag die Macht im Prinzip ausschließlich in seinen Händen, alle Amtsträger wurden nicht wie zuvor von der Bevölkerung, sondern direkt vom Bischof nominiert $^{71}$. Doch bereits ein Jahr später starb der Bischof, und bedingt durch die zunehmenden Spannungen zwischen dem lothringischen Herzogshaus und dem König während der Religionskriege geriet Verdun nun wieder unter herzoglichen Einfluß. Denn Psaumes Nachfolger Nicolas Bousmard, vom Papst gegen den Willen des Domkapitels, des französischen Königs und des Kaisers ernannt, führte nach innen die Politik zur Stärkung der bischöflichen Stellung seines Vorgängers fort und lehnte sich außenpolitisch dem lothringischen Herzog an, der als einziger seine Wahl unterstützt hatte. Bei der Stadtbevölkerung gewann der Herzog durch die Gewährung von Handelserleichterungen ebenfalls zunehmend Sympathien ${ }^{72}$.

1573 wurde die französische Besetzung in Verdun erstmalig zum Anlaß eines Streits um die Gerichtsbarkeit. In jenem Jahr hatte der Magistrat erneut seinen Anspruch auf die Gerichtshoheit auch innerhalb des vom Domkapitel beanspruchten Stadtbezirks cloitre deutlich gemacht und wollte zudem die dort ansässigen Mitglieder des Domkapitels zur Steuer veranlagen. Daraufhin wandten sich die Kanoniker an den französischen König und baten diesen um einen Schutzbrief, der auch gewährt wurde. An den Haustüren im umstrittenen Bezirk wurde ein königliches Wappen angebracht, das jeden, der die Bewohner dennoch vor städtische Gerichte zwingen wollte, zum Majestätsverbrecher machte ${ }^{73}$.

Typisch für diesen frühen Konflikt ist nicht nur die Tatsache, daß hier die königlichen Ansprüche für einen Konflikt der Interessengruppen vor Ort regelrecht instrumentalisiert wurden, sondern auch sein Ausgang: Das Verfahren

${ }^{70}$ Der Brief des Königs und ein weiterer Brief des Herzogs von Lothringen sind abgedruckt bei PICARD, Histoire de Toul, S. 656f.

${ }^{71}$ Das règlement befindet sich in den A.C. Verdun, BB 46, 2.

${ }^{72}$ LE MOIGNE in: GIRARDET (Hg.), Histoire de Verdun, S. 138.

${ }^{73}$ Vgl. die Schilderung der Ereignisse bei PETITOT-BELLAVÈNE, Deux siècles, S. 154f. 
wurde nicht etwa vor den conseil du roi, sondern vor das Reichskammergericht getragen, das wiederum den Bischof von Verdun zum Schlichter bestell$\mathrm{te}^{74}$.

In den Auseinandersetzungen und Ereignissen der sogenannten Religionskriege spielte das lothringische Herzogshaus, insbesondere sein jüngerer Zweig, die Familie der Herzöge von Guise, eine Schlüsselrolle ${ }^{75}$. Durch die enge Nachbarschaft von Trois-Évêchés und Herzogtum sowie die Tatsache, $\mathrm{da}$ ein Großteil der kirchlichen und bedeutenden weltlichen Ämter mit Verwandten oder Parteigängern der Herzogsfamilie besetzt war, mußten die Auseinandersetzungen auch die Geschehnisse in den Trois-Évêchés in jener Zeit entscheidend mitprägen.

In den 80er Jahren des 16. Jahrhunderts führte dies dazu, das Toul und Verdun, die ab 1684 beide in der Hand von Bischof Charles de LorraineVaudemont, einem Angehörigen des Herzogshauses, lagen, fast gänzlich der französischen Kontrolle entzogen wurden. Der Verduner bailli ermöglichte dem Anführer der Liga, dem Herzog von Guise, 1585 Verdun zu besetzen ${ }^{76}$. Zusammen mit dem ebenfalls eroberten Toul ${ }^{77}$ ließ sich der Herzog von Guise die Stadt vom französischen König im Vertrag von Nemours als Sicherheitsplatz der Liga garantieren. Während in Metz mit dem königlichen Gouverneur Épernon ein entschiedener Gegner der Guise die Besetzung durch Ligatruppen verhinderte $^{78}$, wurden die wichtigsten Positionen in Militär und Verwaltung in Verdun im Sinne der Liga besetzt: Ein Parteigänger Guise' wurde neuer Gouverneur in Verdun, der ligatreue bischöfliche bailli zusätzlich Schöffenmeister der Stadtgemeinde.

In den Jahren danach rückte durch das Engagement des Herzogs von Guise in anderen Regionen und dann später durch dessen Ermordung der lothringische Herzog Charles III an dessen Stelle als Stadtherr in Toul und Verdun. Er nahm nach dem Tod des Bischofs Charles de Lorraine-Vaudemont sowohl in Verdun als auch in Toul deutlichen Einfluß auf die Nachfolge im Bischofsamt. In Verdun wurde gegen den Willen des Domkapitels der herzogliche Parteigänger Nicolas Boucher eingesetzt, in Toul wurde unter Charles' Einfluß Christophe de la Vallée gewählt. Letzterer sollte zugunsten eines Mitglieds

\footnotetext{
74 Allerdings konnten die Akten dieses Verfahrens nicht im Bestand »chambre imperiale« der A.D. Moselle gefunden werden. vgl. jedoch PETITOT-BELlavĖNE, Deux siècles, S. 155.

${ }^{75}$ Zur Familie der Guise Michel PERNOT, Les Guises: une mise au point, in: Annales de l'Est 40 (1990) S. 63-117, sowie Jean-Marie ConSTANT, Les Guise, Paris 1984.

${ }^{76}$ LE MOIGNE in: GIRARDET (Hg.), Histoire de Verdun, S. 139.

${ }^{7} \mathrm{Zu}$ den Ereignissen in Toul vgl. die Studien und Quellenexzerpte Cloüets in BnF, N.a.fr. 22617, fol. 14f.

${ }^{78}$ Vgl. dazu auch PERNOT, Les Guises, S. 106f. und SALMON, Society in crisis, S. 238.
} 
des Herzogshauses abdanken, sobald dieses die Volljährigkeit erreicht hatte ${ }^{79}$. Herzog Charles III gebärdete sich damit in Toul und vor allem in Verdun wie zuvor der König: Er garantierte die Freiheiten der Stadt sowie die Oberhoheit des Reiches, und führte gleichzeitig die Benutzung des Salzes aus den herzoglichen Minen ein. Daß er der eigentliche Stadtherr geworden war, zeigte sich auch bei der Nachfolge für Bischof Boucher in Verdun: Hier kam nun der vom Herzog eigentlich für Toul vorgesehene Erric de Lorraine-Chaligny als Bischof zum Zuge ${ }^{80}$. Erst der Vertrag von Folembray (Dezember 1595) etablierte wieder die französische protection in Toul und Verdun, allerdings nur unvollständig, denn das Amt des königlichen Gouverneurs vor Ort sollte in Verdun tatsächlich und in Toul nominell weiterhin von einem Sohn des lothringischen Herzogs ausgeübt werden ${ }^{81}$.

\section{Der Wandel in der französischen Politik nach den Religionskriegen}

Nach dem Ende der Religionskriege setzte in Frankreich unter Heinrich IV. eine innenpolitische Konsolidierungsphase ein, die sich auch in der Politik gegenüber den Trois-Évêchés widerspiegelte ${ }^{82}$. Zunächst wurde 1592 in Metz mit Denis LeBey ein offizieller Stellvertreter des seit sieben Jahren abwesenden président Viart ernannt. Damit endete eine Phase, in der selbst in Metz, das als einzige der lothringischen Städte nicht von Truppen der Liga besetzt worden war, die Bemühungen um die Kontrolle über Gerichtsbarkeit und Verwaltung geruht hatten. Gleichzeitig mit Denis LeBey wurde noch ein weiterer Vertreter des Königs in Metz ernannt: Pierre Joly sollte als procureur général du roi, d.h. als eine Art Kronanwalt über die Rechte des Königs wachen. Sowohl LeBey als auch Joly waren Protestanten.

Dem neuen Kronanwalt Pierre Joly wurden in seiner Emennungsurkunde die gleichen umfassenden Kompetenzen zugestanden wie einem procureur

${ }^{79}$ PICARD, Histoire, S. 668.

${ }^{80}$ LE MOIGNE in: GIRARDET (Hg.), Histoire de Verdun, S. $139 f$.

${ }^{81}$ François de Vaudemont wurde in Toul ein lieutenant de gouverneur par le roi, Jacques de Ligniville de Vannes, an die Seite gestellt, vgl. CABOuRDIN, Bd. 3,1, S. 124-126. Zu Verdun vgl. LE MOIGNE in: GIRARDET (Hg.), Histoire de Verdun, S. 138f.

${ }^{82}$ Die Regentschaft Heinrichs IV. hat sich in der kollektiven Erinnerung Frankreichs bis heute als die Phase der »poule au pot«, der Zeit, in der unter dem »bon roi Henri« jeder Bauer Sonntags ein Huhn auf dem Tisch hatte, erhalten. Vgl. dazu nur MIDDELL, HÖPEL, Einführung, S. 61, sowie Alain BOUREaU, Le Roi, in: Pierre NORA (Hg.), Les lieux de mémoire, 7 Bde., Paris 1984-1992, hier Bd. 3.3, S. 789. 
général an den französischen Parlamenten ${ }^{83}$. Allerdings gab es in Metz lediglich die königliche Schlichtungsgerichtsbarkeit des président, bei dem eine öffentliche Anklage eigentlich weder notwendig noch vorgesehen war. Der neue procureur général hatte zudem laut Ernennungsurkunde einen größeren räumlichen Zuständigkeitsbereich als der président. Während dieser lediglich für Metz und das Pays Messin eingesetzt worden war $^{84}$, war der neue procureur Joly ausdrücklich für Metz, Toul, Verdun, Marsal et pais en deppendans ${ }^{85}$ zuständig, wobei Marsal als königlicher Truppenstandort im Hochstift Metz wohl die Zuständigkeit für das Territorium des Metzer Bischofs bezeichnete. Da es in Toul, Verdun und im Hochstift Metz neben den Militärgerichten keinerlei königliche Justizinstitutionen gab und beim président in Metz eine öffentliche Anklage nicht vorgesehen war, war der neue procureur ein Mann mit großer Machtbefugnis auf dem Papier und kaum vorhandener Zuständigkeit in der Realität. Doch Pierre Joly schaffte sich seine Aufgabe selbst: Seine Berichte, Denkschriften und Briefe legten die Rechte des Königs immer deutlicher und weiter aus, lieferten Argumente gegen das Reichskammergericht und die städtische Regierung und bereiteten in vielerlei Hinsicht das Vordringen weiterer königlicher Institutionen vor. Auf seine Schreiben wird daher an späterer Stelle noch einmal einzugehen sein.

\section{Zuständigkeitskonflikte zwischen königlichen und städtischen Institutionen - drei Fälle aus Metz, Toul und Verdun}

Um die Jahrhundertwende entspannen sich in allen drei Städten heftige Konflikte der städtischen Führungsgremien mit den Statthaltern, die der König dem nominellen Gouverneur François de Vaudemont (einem Bruder des lothringischen Herzogs) in Toul und Verdun zur Seite gestellt hatte, beziehungsweise mit dem Statthaltter des président in Metz, Denis LeBey. Jede dieser Auseinandersetzungen nahm ihren Anfang mit einem Einzelprozeß, bei dem die Zuständigkeit zwischen Militärgerichtsbarkeit und städtischer Justiz umstritten war.

In Metz war der Bürger Martin La Maillotte vor dem président angeklagt worden, weil er angeblich die Frau eines Soldaten ermordet hatte. Eine Beschwerdeschrift, die der Magistrat daraufhin an den König schickte, forderte,

${ }^{83}$ Die Lettres de provision für Joly sind abgedruckt bei ZELLER, Réunion, Bd. 2, S. 343-346 (Anhang 20).

${ }^{84} \mathrm{Vgl}$. die lettre für Selve, abgedruckt bei ZELLER, ibid. S. 348f. (Anhang 22).

${ }^{85}$ Lettre für Joly, ebenfalls ibid. S. 344. 
daß La Maillotte vor einem städtischen Gericht der Prozeß gemacht werden solle. Die darin geäußerten Beschwerden zeigen jedoch auch, wie LeBey das Gericht des président weiterentwickelt hatte: Ihm wurde nämlich von städtischer Seite nicht nur vorgeworfen, er erlasse statt seiner Schlichtertätigkeit Urteile, noch dazu ohne Appellationsmöglichkeit, sondern man beschwerte sich auch, daß mittlerweile mehr Fälle vor dem Présidial-Gericht verhandelt würden als vor den städtischen Institutionen ${ }^{86}$. Die Klagen des Magistrats bezogen sich aber vor allem auf die persönliche Amtsführung LeBeys. Die Metzer brachte wohl weniger die Tatsache auf, daß der neue Vertreter des président regelrechte Urteile sprach, als vielmehr der Umstand, daß er diese nicht wie sein Vorgänger gemeinsam mit den Treize fällte. So wurde LeBey konkret vorgeworfen, er richte ohne seine Beisitzer aus dem Schöffenrat und dem Gericht der Dreizehn. Weiterhin würde er Prozesse selbst dann an sich ziehen, wenn die Parteien wünschten, daß ihr Fall vor den städtischen Gerichten verhandelt werde. LeBey beanspruchte die Kompetenz in allen Beleidigungsprozessen und steckte, so der Vorwurf des Magistrates, die Strafgelder in die eigene Tasche. Dazu habe LeBey die städtischen Richter juges subalternes genannt, eine Bezeichnung, die die Unterordnung der städtischen Gerichte unter den président kennzeichnen sollte und von diesen somit eindeutig als Beleidigung aufgefaßt werden konnte ${ }^{87}$.

Denis LeBey blieb dem Metzer Magistrat ein Ärgernis: Auch in späteren cahiers des doléances von 1602 findet sich die Aufforderung an den König, die schon mehrfach geforderte Absetzung LeBeys zu vollziehen. In der Reaktion auf die Proteste gegen LeBey zeigt sich jedoch die neue Linie aus Paris: Der Statthalter wurde in der Antwort des Königs zwar verwarnt, blieb aber weiter im $\mathrm{Amt}^{88}$.

In Toul war ein tragischer Todesfall im Jahre 1598 der Auslöser eines $\mathrm{Zu}-$ sammenstoßes zwischen dem Statthalter des Gouverneurs und dem Magistrat $^{89}$. Um den kurz zuvor mit Spanien geschlossenen Frieden von Vervins gebührend zu feiern, waren uberall in der Stadt Schüsse abgefeuert worden. Einer dieser Freudenschüsse tötete einen jungen Mann. Da der tödliche Schuß aus einem Haus der Touler Bürgerschaft abgefeuert worden war, begannen die dix justiciers und enquéreurs der Stadt mit den Ermittlungen, indem sie alle Personen, die sich in dem Haus aufgehalten hatten, unter Bewachung stellten. Doch der erst kurz zuvor zum Statthalter ernannte Jacques Ligniville de Van-

${ }^{86}$ EMMERY, Recueil, Bd. 5, Anm. S. 87.

${ }^{87}$ Die Klagen über LeBey und das cahier der drei Stände von Metz sind abgedruckt in den Anmerkungen bei EMMERY, ibid. S. 82-90, hier v.a. S. 88.

${ }^{88}$ Auch dieses cahier ist in den Anmerkungen ibid. S. 90-99 abgedruckt, hier v.a. S. 96.

${ }^{89}$ Die Ereignisse sind geschildert im Livre des enquéreurs, Musée de Toul, S. 118f. Teile davon sind abgedruckt in LEPAGE, Le Livre, S. 177-247, hier S. $216 \mathrm{f}$. 
$\mathrm{ne}^{90}$ beanspruchte ebenfalls die Gerichtsbarkeit in dieser Sache für sein Militärgericht und ließ kurzerhand die Gefangenen in seine Bewachung ubberführen. Sofort schickten die dix justiciers eine Abordnung zum König, die im Einzelfall auch Erfolg hatte: Die Sache wurde wieder an die städtischen Gerichte übergeben ${ }^{91}$. Doch offenbar hatte man in Paris den Regelungsbedarf erkannt, denn im Jahr 1600 wurde durch den Touler Gouverneur ein reiglement pour les differends entre le Gouverneur de la Ville et Cité de Toul et le grand doyen, chanoines et chapitre, magistrat, bourgeois et habitans dudit lieu angekündigt, das am 15. Juli 1600 in der Stadt verkündet wurde ${ }^{92}$. In diesem Regelwerk wurden die gerichtlichen Zuständigkeiten nun eindeutig verteilt: Der Gouverneur war für das Militär, die städtischen Richter oder die des Domkapitels für die übrige Bevölkerung zuständig. Im Falle eines débat entre bourgeois et militaires sollten je ein Vertreter des Gouverneurs und der Stadt gewählt werden, die gemeinsam die Ermittlungen führen und das Urteil sprechen sollten ${ }^{93}$.

Diese Regelung enthielt noch eine weitere bedeutsame Bestimmung: Kirchliche Würden sollten in Zukunft nur noch an Bewohner aus den Gebieten vergeben werden, die entweder unter dem Gehorsam (das Königreich) oder unter der Protektion (Trois-Évêchés) des Königs standen. Damit war ein erster Schritt auch zu einer »Französisierung « (Pimodan) ${ }^{94}$ der Benefizien getan und Mitglieder des lothringischen Herzogshauses sowie deren Parteigänger von ihrem Besitz weitgehend ausgeschlossen.

Ähnlich wie in Toul war im Jahr 1599 auch für Verdun eine Regelung für die Zuständigkeiten von Gouverneur und Zivilgerichtsbarkeit erlassen worden. Auch hier war der Anlaß ein Zuständigkeitskonflikt zwischen Gouverneur und städtischen Gerichten: In einer Auseinandersetzung hatte der örtliche Scharfrichter zwei Schüsse abgegeben, ohne jedoch jemanden zu verletzen. Als ihn die Wachen des Gouverneurs abführen wollten, leistete er Widerstand und beschimpfte diese heftig. Africain d'Haussonville, der Statthalter des Gouverneurs, verurteilte ihn deshalb zum Tode. Der Magistrat zeigte sich empört und schickte eine Deputation zum König ${ }^{95}$. Dieser übergab die Sache seinem Rat, der schließlich im Dezember ein arrêt erließ, das künftigen Konflikten vorbeugen sollte ${ }^{96}$. Diese Regelung wies, anders als die für Toul, bereits einige

\footnotetext{
${ }^{90}$ Ligniville de Vanne wurde 1596 in sein Amt eingesetzt, vgl. PIMODAN, Réunion, S. 261.

${ }^{91}$ Lettres v. 29.10.1599, vgl. auch Livre des enquéreurs, ed. LEPAGE, S. 217. PIMODAN, Réunion, S. 263-266.

92 BnF, fr. 16889, fol. 275 und fol. 258; N.a.fr. 7099, fol. 174-177 sowie Dupuy 124, fol. 232-235.

${ }^{93}$ BnF, fr. 16889, fol. 281.

${ }^{94}$ PIMODAN, Réunion, S. 269.

${ }^{95}$ Petitot-Bellavène, Deux siècles, S. 223f.

${ }^{96}$ 1.12.1599. BnF, Cinq-Cents Colbert 440, fol. 107-109, N.a.fr. 7101, fol. 111-114.
} 
Fälle, auch wenn Bürger beteiligt waren, als eine Art cas royaux eindeutig königlichen Gerichten bzw. Amtsträgern zu. Genau wie in Toul wurde zudem bestimmt, daß nur noch Bewohner Frankreichs und der Trois-Évêchés in geistliche Würden zugelassen werden sollten ${ }^{97}$.

\section{Der Kampf um den Treueid}

Der président, der zuvor eigentlich nur in Metz agiert hatte, erschien nach diesen Ereignissen erstmals auch in Toul und Verdun: 1601 sollten alle Amtsträger dieser beiden Städte vor dem président Jacques Viart einen offiziellen Treueid auf den König von Frankreich leisten ${ }^{98}$. Begründet wurde der Schritt durch die lange Besetzung von Toul und Verdun mit Truppen des lothringischen Herzogs während der Religionskriege. Viarts Mission erwies sich als schwierig: Sowohl in Toul als auch in Verdun schien es den Magistraten zunächst als Verrat am Kaiser, diesen Eid zu leisten ${ }^{99}$.

In Verdun gelang es dem président allerdings schnell, diese Vorbehalte zu zerstreuen, und nur wenige Tage nach seiner Ankunft nahm er nicht nur vom Magistrat und vom Rat der Stadt, sondern auch vom Bischof, dem Domkapitel und deren Amtsträgern den Treueid auf den König als seigneur protecteur entgegen ${ }^{100}$. Daraufhin entwickelte sich in der Maasstadt sogar eine regelrechte Volksbewegung, in der viele Bürger danach strebten, den Eid noch einmal persönlich zu leisten, obwohl der Magistrat dies bereits ausdrücklich in ihrem Namen getan hatte ${ }^{101}$.

Der Treueid des Magistrats und des Bischofs in Toul hingegen geschah nicht zur vollen Zufriedenheit des Königs und seines Präsidenten: Die Bürger hatten nach langen Diskussionen 1602 zugestanden, den König als ihren protecteur, nicht jedoch als seigneur protecteur anzuerkennen. Und auch der

${ }^{97}$ A.C. Verdun, BB 46, 3.

${ }^{98}$ Der Auftrag für Viart findet sich in A.C. Verdun AA 5, 4; vgl. für Toul PIMODAN, Réunion, S. 269.

${ }^{99}$ Vgl. ibid. S. 269f.; PetiTOT-Bellavène, Deux siècles, S. 229f.

${ }^{100}$ Der städtische Eid ist protokolliert in A.C. Verdun BB 3. Der Eid des Bischofs in BnF, N.a.fr. 7101, fol. 147-150.

${ }^{101}$ Vgl. Petitot-Bellavène, Deux siècles, S. 233. Auf diese Ereignisse wird an anderer Stelle noch einmal eingegangen. 
Touler Bischof hatte zwar den Eid geleistet, das Wort seigneur jedoch sorgfältig vermieden ${ }^{102}$.

Nachdem er als président erstmals in Toul und Verdun Präsenz gezeigt hatte, war Jacques Viart seit 1602 wieder persönlich in Metz anwesend. Genau wie sein Statthalter Denis LeBey geriet auch er in den Rangkonflikt mit städtischen Gerichten. Viart beanspruchte nicht nur die Teilnahme, sondern den Vorsitz bei allen Sitzungen der städtischen Gerichte. Dieser Konflikt, kaum geschlichtet durch eine hinhaltende lettre des Königs ${ }^{103}$, schwelte noch, als Heinrich IV. zu seiner Reise nach Lothringen aufbrach.

Währenddessen wurde in Verdun nach dem Metzer Vorbild Anfang des Jahres 1603 ebenfalls das Amt eines procureur du roi geschaffen ${ }^{104}$. Das Amt fiel an Humbert de la Plume, der zuvor als procureur in Diensten des Domkapitels gestanden hatte ${ }^{105}$. Ähnlich wie Pierre Joly in Metz war auch er eigentlich ein Amtsträger ohne Aufgabe, denn ein königliches Gericht existierte in Verdun nicht. Möglicherweise wurde zum gleichen Zeitpunkt auch in Toul ein procureur du roi ernannt ${ }^{106}$.

\section{Der Besuch des Königs}

Die Reise des französischen Königspaares nach Lothringen war ein weiterer Baustein auf dem Weg der Trois-Évêchés zur französischen Provinz. Der König traf am 9. März 1603 in Verdun ein und reiste von dort weiter nach Metz, wo sich der Hof vom 14. März bis zum 1. April aufhielt. Dem König wurde ein prächtiger Empfang bereitet, dessen außergewöhnlicher Prunk in den Stichen des Prachtbandes »Voyage du Roy à Metz, à l'occassion d'iceluy, en-

${ }^{102}$ La Vallées Treueid findet sich in der BnF, N.a.fr. 7099, fol. 178f., der des Magistrats in N.a.fr. 7099, fol. 180. Die Auseinandersetzung um das Wörtchen Seigneur im Treueid zog sich über Monate hin, vgl. dazu auch das Kapitel VIII.2.

${ }^{103}$ Le Roi veut et ordonne que les supplians soient maintenus en tous \& chacuns leurs privilèges, \& jouissent pleinement des degrés de Jurisdiction qui leur sont attribués et permis par les Rois ses prédécesseurs, \& en usent ainsi qu'ils ont bien et duement fait par le passé, reservant aussi au président, pour la justice à Metz, les pouvoirs, fonctions, facultés préséance, dignité \& autorité attribués audit État,... EMMERY, Recueil, Bd. 5, S. 92.

${ }^{104}$ Emennung La Plumes in der BnF, N.a.fr. 7101, fol. 143f. (21.1.1603). Sie wird damit begründet, daß der König neben dem Gouverneur keinen weiteren Amtsträger in der Stadt habe. In den Stadtratsprotokollen von Verdun wird allerdings bereits für 1600 ein procureur du roi genannt, vgl. A.C. Verdun BB 3, 1600.

${ }^{105}$ BnF, N.a.fr. 7101, fol. 115.

${ }^{106} \mathrm{Ab} 1611$ existierte sicher ein procureur du roi in Toul, der jedoch nach Roux bereits von Heinrich IV., also vor Mai 1610, eingesetzt wurde. RouX, in: Position des Thèses, S. 80. 
sembles les signes de resjouissance faits par les habitans pour honorer l'entrée de Sa Majesté « festgehalten ist. Das Buch wurde vom Metzer Schöffenmeister Abraham Fabert in seiner Druckerei herausgegeben ${ }^{107}$. Der Text stammte von Pierre Joly, dem procureur du roi in Metz. Das Werk ist jedoch weniger eine Hommage an den König, als vielmehr an jene, die seinen Empfang gestaltet haben: Unter den Teilnehmern findet sich die gesamte Oberschicht der Stadt $^{108}$. Während des Aufenthaltes in Metz wurde auch die Berührung der Skrofelnkranken praktiziert. Durch seinen Besuch erreichte der König, daß die Stadt ihm einen Großteil ihrer Geldforderungen aus älteren Krediten erlie ${ }^{109}$.

Auch in Toul war der Empfang mehr als prächtig. Im Livre des enquéreurs wird vom militärischen Prunk berichtet, mit dem der Einzug des Königs in die Stadt geschah. Auch hier erreichte der König durch seine persönliche Anwesenheit viel. Der Magistrat zeigte nun endlich seine Unterwürfigkeit: le magistrat ayant un genouil fléchis bas, fit sa harangue au bout du bail SaintNicolas, berichtete das Livre des enquéreurs ${ }^{110}$. Der Versuch des Königs, dem von ihm stets besonders protegierten Domkapitel seine weltlichen Besitzrechte abzukaufen, scheiterte allerdings ${ }^{111}$.

Während seines Aufenthaltes in Verdun war dem König vom Rat, dem Magistrat und den Bürgern der Stadt ein ausführliches cahier des doléances, vor allem zu Fragen der Kompetenzen von städtischen und königlichen Beamten, vorgelegt worden, das er sogleich beantwortete ${ }^{112}$. Auch der Magistrat von Toul wandte sich anläßlich des Besuches mit einer Supplik an den König ${ }^{113}$. Weitere Regelungen wurden vor Ort getroffen oder präzisiert: So erneuerte der König die bereits in den Reglements für Toul und Verdun enthaltene Anordnung, daß Ausländer keine Benefizien besitzen dürften, und erhob sie damit in Gesetzesrang ${ }^{114}$. Bezeichnend ist auch, daß eine der wenigen gefundenen Begnadigungen eines Bewohners der Trois-Évêchés durch den französischen König während seines Aufenthaltes vor Ort stattgefunden hat ${ }^{115}$. Zuvor war dieses Recht vom Kaiser ausgeübt worden, und gemeinsam mit der Frage der

${ }^{107}$ Metz 1610, vgl. RoNSIN, Répertoire bibliographique, S. 29. Exemplare dieses Werkes finden sich u.a. in der Stadtbibliothek Metz, in der Stadtbibliothek Nancy und in der BnF. Die Autorin hat ein weiteres Exemplar der Bibliothèque Mazarine verwendet.

${ }^{108}$ HENNEQUIN, HIPP, La vie littéraire, in: Histoire de la Lorraine. La vie intellectuelle, S. 72.

${ }^{109}$ LE MOIGNE, Histoire de Metz, S. 236.

${ }^{110}$ Musée de Toul, Livre des enquéreurs zum Jahr 1603.

111 Cabourdin, Histoire de Lorraine, Bd. 3,1, S. 157.

${ }^{112}$ BnF, N.a.fr. 7101, fol. 145-150.

${ }^{113}$ A.C. Toul, AA 8.

${ }^{114} \mathrm{BnF}$, N.a.fr. 22680 , fol. 2.

115 18.3.1603, BnF, N.a.fr. 7101 , fol. 141 f. 
Treueide sollte es auch bei der Suche nach den altangestammten Rechten Frankreichs in den Trois-Évêchés einen wichtigen Punkt darstellen.

Nach einer späteren Denkschrift von 1631/32 war zum Zeitpunkt der Reise des Königs nach Lothringen im Jahr 1603 auch erstmalig die Idee eines Parlaments für die Trois-Évêchés aufgekommen ${ }^{116}$. Doch nachdem der König die Region wieder verlassen hatte, wurden die Parlamentspläne offenbar auf Eis gelegt, denn in den Dokumenten dieser Jahre fanden sie keinen Niederschlag. Die oben genannte Denkschrift erklärte das Scheitern der frühen Pläne mit finanziellen Gründen und dem Savoyenkrieg ${ }^{117}$.

\section{Die Rolle des président und der Pariser Gerichte in der Berufungsdiskussion}

Den stets weiter schwelenden Streit zwischen dem Magistrat von Metz und dem président Jacques Viart um den Vorsitz bei Sitzungen der städtischen Gerichte hatte der französische König auch während seiner persönlichen Anwesenheit nicht endgültig beilegen können. Heinrich IV. hatte sich vor Ort ausdriicklich für den Vorsitz des président ausgesprochen, doch als der Magistrat einige Tage später von dieser Entscheidung erfuhr, schickte er sogleich eine Abordnung, um deren Rücknahme zu erreichen. Die Sache blieb ohne Ausgang; schließlich verließ Viart die Stadt unverrichteter Dinge ${ }^{118}$.

Erst bei seiner Rückkehr im Jahr 1605 nahm der président die Frage des Vorsitzes wieder auf, und konnte diesmal auch eine endgültige Bestätigung seines Rechts erhalten. Ausgekostet hat er diesen Triumph aber nicht mehr, denn er trat zugunsten seines designierten Nachfolgers Lazare de Selve von seinem Amt zurück ${ }^{119}$. Mit dem Metzer Magistrat hatte man nun in Paris versucht, einen Kompromiß zur Güte zu schließen: Selve, der neue président, sollte sein Recht zum Vorsitz nur dreimal im Jahr wahrnehmen. In der Praxis scheiterte allerdings selbst diese Vereinbarung ${ }^{120}$.

Statt dessen erhielt der président Selve außerhalb von Metz neue Kompetenzen. Schon in den Jahren zuvor hatte es in Verdun ständig Konflikte um die

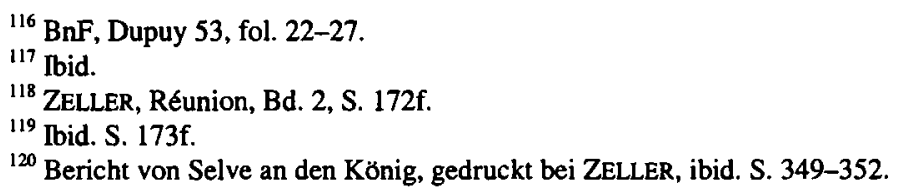


Gerichtsbarkeit gegeben ${ }^{121}$. Humbert de la Plume, der 1603 neu eingesetzte procureur du roi in Verdun, und der Statthalter des Gouverneurs Africain d'Haussonville unternahmen immer wieder Versuche, Gerichtskompetenzen in königliche Hände zu bringen. So hatte la Plume 1604 versucht, Verfahren vor dem Militärrichter, dem prévôt des maréchaux entscheiden zu lassen ${ }^{122}$. An den Forderungen nach einer sogenannten chambre de justice, die die Appelle an das Reichskammergericht ersetzen sollte, hatte der procureur $d u$ roi ebenfalls tatkräftig mitgewirkt ${ }^{123} .1606$ sendeten einige Bürger von Verdun offenbar ebenfalls lanciert von Humbert de la Plume - eine Bittschrift an den König, in der sie diesen ersuchten, die Gerichtsbarkeit von Bischof und Stadt abzuschaffen und durch ein königliches Gericht zu ersetzen ${ }^{124}$.

Nach dem gescheiterten Versuch des conseil du roi im Jahr 1603, Streitigkeiten zwischen königlicher und städtischer oder bischöflicher Justiz vor dem Présidialgericht in Vitry entscheiden zu lassen ${ }^{125}$, erließ der königliche Rat 1607 ein règlement - auf vielfaches Ersuchen der Bürger von Verdun, wie in der Begründung stand. Dieses setzte fest, daß Berufungen gegen die Urteile der bischöflichen Gerichte von Verdun in Zukunft vor dem Gericht des président von Metz entschieden werden sollten ${ }^{126}$. Den daraufhin zum Protest nach Paris entsandten Vertretern des Magistrats wurden allerdings die Jurisdiktionsrechte der Stadt Verdun bestätigt - der président oder sein Vertreter vor Ort sollten lediglich die Berufungen vor dem Reichskammergericht ersetzen ${ }^{127}$. Doch im Oktober 1608 ließ Humbert de la Plume die erste Sitzung eines neuen königlichen Présidial-Gerichts per Plakat ankündigen. Daß dieses lediglich das Reichskammergericht ersetzen sollte, wurde nicht erwähnt ${ }^{128}$. Eine daraufhin vom Verduner Magistrat einberufene Ständeversammlung untersagte allen Bürgern und Advokaten der Stadt, vor diesem Gericht zu erscheinen, und protestierte erneut beim König, der daraufhin seinen Vertretern vor Ort die Errichtung einer solchen Institution mit umfassender Berufungsgerichtsbarkeit zum fünften Mal innerhalb eines Jahres ausdrücklich untersagen mußte ${ }^{129}$.

${ }^{121} \mathrm{Vgl}$. nur die Beschwerden im oben genannten cahier des doléances, BnF, N.a.fr. 7101, fol. $145-150$.

${ }^{122}$ Ibid. fol. $163 f$.

${ }^{123}$ A.C. Verdun, BB 41604 und 1606. Zur Rolle la Plumes vgl. auch PIMODAN, Réunion, S. 363.

${ }^{124}$ PettTot-Bellavène, Deux siècles, S. 342. Das Original dieser requête konnte leider nicht gefunden werden.

${ }^{125}$ Diese Regelung in BnF, N.a.fr. 7101, fol. 145-150.

${ }^{126}$ 12.7.1607, gedruckt bei EMMERY, Recueil, Bd. 1, Anm. S. 178-180.

${ }^{127}$ Petitot-Bellavène, Deux siècles, S. 248.

${ }^{128}$ A.C. Verdun BB 4 (1608).

129 Le MoIGNE in: GiRARDET (Hg.), Histoire de Verdun, S. 142. Petitot-Bell.AVÈnE, Deux siècles, S. 249. 
In Toul ging man nach dieser Erfahrung vorsichtiger vor. Auch hier hatte es, wie bereits dargestellt, immer wieder Auseinandersetzungen mit den Vertretern des Königs um Gerichtskompetenzen gegeben. So hatte beispielsweise im Sommer 1603 der Statthalter des Gouverneurs, Jacques Ligniville de Vanne, der wegen Totschlags eines Bürgers ermittelte, sogar den Schöffenmeister verhaften lassen ${ }^{130}$. Ein erneutes königliches règlement präzisierte daraufhin im Juli 1604, in welchen Fällen die Vertreter des Königs ermitteln und Recht sprechen durften ${ }^{131}$.

Im April 1607 starb der Bischof von Toul, Christophe de la Vallée. Erneut kam es zu einem Kompetenzgerangel: Ligniville de Vanne wollte das Bistum für seinen Neffen gewinnen und verband sich dazu mit dem Domkapitel, während sein Statthalter energisch auf einer königlichen Mitsprache in der Besetzungsfrage bestand ${ }^{132}$. Auch der Herzog von Lothringen intervenierte, jedoch konnte er das Bistum ebensowenig für den minderjährigen Henri de Lorraine gewinnen wie der Gouverneursvertreter dies für seinen Verwandten konnte ${ }^{133}$. Dennoch wurde mit Jean des Porcelets de Maillane, Abt von Saint-Mansuy vor den Toren der Stadt, in Rom ein Kandidat des lothringischen Herzogs zum neuen Bischof von Toul ernannt ${ }^{134}$ - zumindest bis Charles de Lorraine (sein älterer Bruder Henri war mittlerweile verstorben) das benötigte Alter für die Bischofswürde erreicht hatte. Porcelets de Maillane ersuchte den Kaiser nicht um seine Investitur, und auch sein Amtseid enthielt keinen Hinweis mehr auf die Rechte des Kaisers ${ }^{135}$. Statt dessen mußte der neue Touler Bischof vor dem französischen König einen Treueid ablegen. Zwar zögerte er zunächst, doch schließlich war der Begriff seigneur protecteur Teil der geleisteten Eidesformel.

Im Jahr 1607 richteten wie in Verdun auch in Toul etwa zwei Dutzend Bürger eine Bittschrift gegen die longues et immortelles procedures vor dem Reichskammergericht an den französischen König. Dies geschah offensichtlich unter dem Einfluß des Sieur du Mesnil, Statthalter des Gouverneurs vor $\mathrm{Ort}^{136}$. Daraufhin wurde die für Verdun getroffene Regelung auch auf Toul

\footnotetext{
${ }^{130}$ Musée de Toul, Livre des enquéreurs, 1603, S. 127. Vgl. auch die Beschwerde des Stadtrates von Toul an den König in A.C. Toul, AA 8.

${ }^{131}$ 6.7.1604, BnF, Dupuy 124, fol. 232-235 und N.a.fr. 7099, fol. 182-187.

${ }^{132}$ Vgl. dazu ibid. fol. 190 und 192.

${ }^{133}$ PIMODAN, Réunion, S. 344-347.

${ }^{134} \mathrm{Zu}$ Porcelets de Maillane und seiner großen kirchlichen Bedeutung vgl. Michel PERNOT, Un acteur de la Réforme catholique en Lorraine: Jean Des Porcelets de Maillane, évêque de Toul (1608-1624), in : René Tavenaux (Hg.), Saint Pierre Fourier et son temps, Nancy 1992, S. 73-84.

${ }^{135}$ PIMODAN, Réunion, S. 353.

${ }^{136}$ Institut, Godefroy 355, fol. 2; BnF, fr. 16889, fol. 8; und N.a.fr. 7099, fol. 9f. Alle Exemplare dieses Dokuments sind undatiert, das Exemplar des Instituts trägt die Unterschriften
} 
ausgedehnt ${ }^{137}$. Daß das Gesuch, die Berufungen vor dem Reichskammergericht abzuschaffen, jedoch genau wie in Verdun nur einen Bruchteil der Einwohnerschaft repräsentierte, wurde bei der Reaktion der Ständevertreter deutlich. Nun sprachen sich die Bürger von Toul eindeutig für das Reichskammergericht und ihre ancien façon de vivre, die sie behalten wollten, aus ${ }^{138}$. Sie betonten, daß sie nie über die hohen Kosten geklagt hätten und befürchteten, vor dem Kaiser wegen Felonie angeklagt zu werden ${ }^{139}$. Die Notiz eines weiteren Protestschreibens läßt sogar einen noch weit schärferen Ton vermuten: Hier ist nicht nur die Rede davon, daß diese Veränderung offence dieu, blesse les hommes \& apporte aucune bonne fin, sondern es wird auch - in Anspielung auf den Statthalter du Mesnil - deutlich gemacht, daß die einzigen, die davon profitierten, einige particuliers officiers seien ${ }^{140}$. Auch der neue Bischof Jean des Porcelets de Maillane brachte trotz des Treueides im Sommer 1608 seine Ansprüche auf ungestörte Ausübung seiner droitz, jurisdiction et créations de ses officiers zum Ausdruck ${ }^{14 !}$.

Die Frage blieb offenbar in der Schwebe, denn ein Jahr später ermahnte der König Heinrich IV. in einem reglement, das zunächst kirchliche Fragen behandelte, die Bürger erneut, daB seine Anordnungen zur Appellation eingehalten werden sollten ${ }^{142}$. Interessant ist hierbei der Ton: Die eigenen Amtsträger wurden vom König ermahnt, mit Gerechtigkeit und Milde, equité et douceur, vorzugehen, den Appellierenden versicherte er, daß ihnen so abgeholfen werde wie es gerecht sei. Wie gespannt die Lage war, zeigt jedoch vor allem der folgende Paragraph seines règlement: Le Roi veut croire que l'animosité qu'ont témoigné envers ses Officiers ceux de la Justice de ladite Ville, cessera, \& qu'ils se comporteront à l'avenir, \& vivront ensemble comme ils doivent. Zur Beförderung dieses Ziels und zur Befriedung der offenbar sehr schwierigen Verhältnisse nutzte der französische König einen geschickten Schachzug: Er entzog die beiden verfeindeten Parteien in Toul für zwei Jahre gänzlich der jeweils anderen Gerichtsbarkeit. Deutlich wird in diesem règlement ebenfalls die Entwicklung und Verwendung der Theorie der cas royaux: So wird ausgeführt, daß das Verbrechen der Falschmünzerei auch in Toul von königlichen

von 24 Bürgern der Stadt Toul, darunter an zweiter Stelle die Mesnils. Die Datierung folgt PIMODAN, Réunion, S. 364.

${ }^{137}$ Der arrêt des königlichen Rates konnte nicht gefunden werden, vgl. aber PIMODAN, Réunion, S. 365, und eine Erwähnung in einem Edikt aus dem Jahr 1611 (dort allerdings fälschlich auf 1605 datiert) bei EMMERY, Recueil, Bd. 1, S. 173.

${ }^{138}$ A.C. Toul AA 8 und BnF, N.a.fr. 7099, fol. 7f. Auch BnF, fr. 16889, fol. 289 und Dupuy

124 , fol. 244, dort allerdings deutlich schärfer formuliert.

${ }^{139}$ A.C. Toul AA 8 und BnF, N.a.fr. 7099 , fol. 7 f.

${ }^{140} \mathrm{BnF}$, fr. 16889, fol. 289 und Dupuy 124, fol. 244.

141 AMAE, CP Lorraine 7, fol. 128.

${ }^{142}$ Règlement vom 1.8.1609, gedruckt bei EMMERY, Recueil, Bd. 1, Anm. S. 171-173. 
Richtern geahndet werden solle, weil es direkt die Autorität des Königs beschädige.

Im Sommer 1611 wurde erneut versucht, die sowohl in Toul als auch in Verdun noch immer umstrittene Appellation vor dem président als verbindlich durchzusetzen ${ }^{143}$. Doch die lange Zeit der Unklarheit hatte längst Fakten geschaffen. Zwar hatten die Berufungen vor dem Reichskammergericht tatsächlich ein Ende gefunden, doch statt des président in Metz und seiner Vertreter in den beiden anderen Bischofsstädten waren die Pariser Gerichte an die Stelle des Reichskammergerichts getreten. Der conseil du roi war aufgrund seiner gewohnheitsrechtlichen Zuständigkeit in allen Kompetenzstreitigkeiten zwischen einzelnen Gerichten und wegen seines hohen Ansehens geradezu dazu prädestiniert, in den Jahren nach 1598 die entscheidende Rolle zu spielen ${ }^{144}$. Hierbei ging es jedoch nicht nur um Einzelfallentscheidungen, sondern auch um die grundsätzliche Regelung vieler Fragen, die den conseil schließlich fast das gesamte Verfahrensrecht in Metz, Toul und Verdun gestalten lie $B^{145}$. Dort griff man schließlich zu Abwehrmaßnahmen: In Metz hatte der Rechtsstreit des Godefroy d'Eltz im Jahr 1608, dessen Fall zwischen président und dem Gericht der Dreizehn umstritten war, sogar zu einem Verbot des Magistrats an alle Bürger geführt, vor dem conseil du roi Klage einzureichen ${ }^{146}$.

Die Klagen vor dem conseil machen deutlich, $\mathrm{da}$ der Wunsch nach einem königlichen Gericht, auf den sich der König in seinen règlements explizit bezog, zumindest in einigen Bevölkerungsteilen also tatsächlich existiert haben muß. Ab etwa 1611 tendierte der conseil du roi jedoch dazu, die Kläger wieder vor städtische Gerichte oder den président von Metz zu verweisen.

Daneben finden sich auch Hinweise auf Versuche, aus den Trois-Évêchés an das Parlament von Paris zu appellieren. Schon 1603 hatte der Stadtrat von Verdun klarstellen müssen, daß die Stadt nicht zum Zuständigkeitsbereich des Pariser Gerichts gehöre ${ }^{147}$, und in den Jahren 1605, 1607 und 1609 hatten Kläger aus Metz wiederholt versucht, ihre Ziele vor dem Pariser Parlament zu verfolgen $^{148}$. Eine neue Qualität bekamen diese Bestrebungen jedoch nach 1611 , als erneut versucht wurde, Berufungen vor dem président von Metz in Toul und Verdun durchzusetzen.

${ }^{143}$ Lettre patente vom 23.7.1611 und vom 17.8.1611, ausgeweitet auf Toul, gedruckt bei EMMERY, Recueil, Bd. 1, Anm. S. 173-175 und S. 180 f.

${ }_{144}$ Zum conseil du roi vgl. ANTOINE, Le Fonds, und LEBIGRE, Justice du Roi, S. $49 f$.

${ }^{145}$ Vgl. v. a. die arrêts von 1598 zum Rechtsstreit zwischen Domkapitel und Magistrat von Toul, BnF, N.a.fr. 7099, fol. 163f., von 1599 zum Verfahren zwischen Bischof und Magistrat von Verdun und dem Gouverneur, BnF, Cinq-Cents-Colbert 440, fol. 107-109, und von 1611 zur Interpretation des arrêt von $1599 \mathrm{zu}$ Verdun, BnF, N.a.fr. 7101, fol. $215 f$.

${ }^{146}$ ZELLER, Réunion, Bd. 2, S. $180 \mathrm{f}$.

${ }^{147}$ A.C. Verdun BB 4 (1603).

${ }^{148}$ ZELLER, Réunion, Bd. 2, S. 177-179. 
In Toul wollte das von Heinrich IV. stets besonders privilegierte Domkapitel $^{149}$ nun statt des président ganz offiziell das Parlament von Paris als höchste Berufungsinstanz etablieren. Dies wurde auch gewährt ${ }^{150}$. Damit allerdings erfuhr die Position des président in Toul eine dauerhafte Schwächung, da die Untertanen des Bischofs und die Stadtbürger nicht verstanden, warum sie nicht auch vor den renommierteren Richtern in Paris Rechtshilfe suchen soll$\operatorname{ten}^{151}$.

Auch in Verdun traf der erneute Vorstoß zugunsten des président auf Widerstand: Schon 1610 hatte Bischof Erric de Lorraine seine Amtsträger ermahnt, nichts zuzulassen, was seiner Autorität schaden könne ${ }^{152}$. Und so wehrten sich diese auch erneut heftig gegen die Durchsetzung des président als Berufungsinstanz für die bischöflichen Gerichte ${ }^{153}$. Widerstand kam auch vom Domkapitel $^{154}$ und dem Bischof selbst ${ }^{155}$. Schließlich forderte das Domkapitel von Verdun, das Parlament von Paris als Berufungsgericht einzusetzen, allerdings ohne Erfolg ${ }^{156}$. Gleichzeitig traf von Seiten des ehemaligen bischöflichen bailli in Verdun, der von seinem Dienstherren kurz zuvor wegen mangelnder Loyalität abgesetzt worden war, ein Gutachten ein, das dieser zusammen mit dem späteren lieutenant du roi Jean Gillet angefertigt hatte. Beide forderten erneut ein eigenes königliches Gericht, eine chambre royale direkt in Verdun ${ }^{157}$. Auch der procureur du roi in Metz setzte sich per Gutachten für eine solche chambre souveraine ein ${ }^{158}$.

Zunächst jedoch sollte am président als Appellationsinstanz für alle drei Städte festgehalten werden. Die Häufung der königlichen Anordnungen zur Durchsetzung von dessen Berufungshoheit in der Folgezeit spricht jedoch für

${ }^{149}$ Drei jeweils sehr weitgehende Bestätigungen der Rechte und Befreiungen von Lasten (z.B. durch Einquartierungen) durch Heinrich IV. wurden gefunden: von 1596, BnF, N.a.fr. 7099 , fol. 161f.; von 1600, ibid. fol. 165-169 und von 1609, ibid. fol. 204-206.

${ }^{150} 2.6 .1612$, ibid. fol. 211-214.

151 Das Domkapitel nannte in seinem Gesuch eindeutig das größere Renommee des Pariser Parlaments und seiner Richter als Grund für sein Ersuchen, dort Berufung einlegen zu dürfen. Vgl. die referierte requête ibid.

${ }^{152}$ Brief v. 6.8.1610, BnF, N.a.fr. 7101, fol. 209f.

${ }^{153}$ Ibid. fol. 219.

${ }^{154}$ Ibid. fol. 223.

155 Ibid. fol. 261-267.

${ }^{156}$ Ibid. fol. 379-382.

157 A.D. Meuse 11 F 7, 66. Das Schreiben ist offenbar mit Spezialtinte unterschrieben und undatiert, kann jedoch aus dem Kontext heraus eingeordnet werden. Der Autor Saintignon war im August 1609 seines Amtes enthoben worden, vgl. Institut, Godefroy 265, fol. 55 und 61. Er war zuvor als besonders königstreu aufgefallen: So hatte er unter anderem Aktenstücke zur Untermauerung königlicher Ansprüche in Verdun gesammelt und stand im Briefkontakt mit dem Kanzler (vgl. Godefroy 265, fol. 24-27). Seine Biographie wird später noch einmal aufgegriffen werden.

${ }^{158}$ BnF, Dupuy 53, fol. 14-21. 
deren Wirkungslosigkeit: Nach Bekanntwerden der Proteste des Touler Domkapitels mußte der König im April 1612 ausdrücklich Berufungen von städtischen Gerichten in Toul vor dem Pariser Parlament verbieten ${ }^{159}$, im Oktober 1613 wurden erneut die Berufungskompetenzen des président für Toul und Verdun bestätigt ${ }^{160}$, im Mai 1615 regelte ein erneuter arrêt dessen Zuständigkeit in Toul ${ }^{161}$, und im Dezember 1618 sowie 1624 mußten wieder Verbote an das Parlament von Paris bzw. die Untertanen des Touler Bischofs ergehen, die Berufungen von Touler Gerichten nach Paris ausdrücklich ausschlossen ${ }^{162}$.

Während die Situation in den Städten durch die wiederkehrenden Auseinandersetzungen und gegenseitigen Beschwerden gut dokumentiert ist, ist über die Lage in den kleineren Orten der bischöflichen Territorien wenig herauszufinden. Im Hochstift Metz, das seine Selbstständigkeit am längsten bewahren konnte, schien sich der Wandel der königlichen Politik unter Heinrich IV. kaum bemerkbar zu machen. Seit der sogenannten guerre cardinale, in der der Bischof Kardinal Charles de Lorraine mit Hilfe seiner Vasallen seinen königstreuen bailli Salcede in Schach gehalten hatte, war das Hochstift weitgehend unabhängig geblieben ${ }^{163}$. Die Institutionen des Metzer Bischofs in Vicsur-Seille schienen weiterhin völlig außerhalb der Kontrolle königlicher Instanzen: Hier wurde beispielsweise noch immer ausschließlich nach Speyer appelliert ${ }^{164}$.

Die Dinge schienen sich erst zu ändern, als der einflußreiche Kardinalbischof am 27.11.1607 verstarb. Nun sorgte der König in Anwendung seiner Edikte von 1603 dafür, daß jemand auf den Bischofsstuhl kam, der ihm vollkommen ergeben war. Ohne Widerspruch designierte das Metzer Domkapitel auf Aufforderung des königlichen Gouverneurs den unehelichen Sohn des Königs, Henri de Bourbon-Verneuil ${ }^{165}$. Da dieser jedoch erst sieben Jahre alt war, erhielt er lediglich eine bulle d'access au évêché, und zunächst wurde Anne de Perusse d'Escars, Kardinal de Givry, Bischof in Metz ${ }^{166}$. Der betagte Anne de Givry, der in der französischen Geistlichkeit viel Respekt genoß, wurde im Oktober 1608 ernannt, jedoch kam er erst fast ein Jahr später - und

\footnotetext{
${ }^{159}$ BnF, N.a.fr. 7099, fol. 219 f.

${ }^{160}$ BnF, N.a.fr. 7101 , fol. 396.

${ }^{161} \mathrm{BnF}$, N.a.fr. 7099 , fol. $227 f$.

162 Ibid. fol. 265-267, 268-270.

${ }^{163}$ Eine Schilderung dieser guerre Cardinale findet sich in der BnF, Dupuy 334, fol. 70-93. $\mathrm{Zu}$ den Ereignissen und ihren Folgen für das Hochstift vgl. auch PROST, Albestroff, S. 53f.

${ }^{164}$ Vgl. zu den Berufungen am Reichskammergericht Kapitel IV.4.

${ }^{165}$ ZELLER, Réunion, Bd. 2, S. 220.

${ }^{166}$ Die Ernennung Anne de Givrys war offenbar ein Kompromiß zwischen den herzoglichlothringischen und den königlichen Interessen, denn bereits bei der Frage der Ernennung von Henri de Bourbon hatte der Herzog in Rom auf eine Nomination Givrys hingewirkt. Vgl. den Brief von Porcelets de Maillane an den lothringischen Herzog in dieser Sache: A.D. Meurthe-Mos. 4 F 2, fol. 160.
} 
nur widerwillig - in sein Bistum ${ }^{167}$. Schon bald zeigte sich jedoch, daß Anne de Givry durchaus eigene politische Ideen verfolgte. Zwar suchte er beim Kaiser nicht um die Einsetzung in seine weltlichen Rechte nach, aber er nahm seine Aufgabe zu ernst, um nur als Werkzeug des Königs zu agieren. Statt einer erwarteten Zusammenarbeit kam es 1609 zum Konflikt mit dem königlichen Gouverneur in Metz, Jean-Louis d'Épernon. Dieser forderte vom Bischof die Anerkennung eines königlichen Patentes, das besagte, daß ihm als Gouverneur nicht nur in der Stadt Metz, sondern auch en toutes les villes places et lieux de l'estendue des évesché de Metz absoluter Gehorsam geleistet werden solle. Anne de Givry weigerte sich, diesen Eingriff in seine Souveränität anzuerkennen und erreichte schließlich sogar die Suspension des Edikts ${ }^{168}$.

Als ein Jahr darauf auf den ermordeten Heinrich IV. sein Sohn Ludwig XIII. folgte, machte der Metzer Gouverneur Épernon einen weiteren Versuch, die königliche Autorität auszudehnen und verlangte nun einen Treueid von den Untertanen des Hochstifts für den neuen König. Erneut widersetzte sich Anne de Givry erfolgreich ${ }^{169}$. Die Beziehungen zwischen Gouverneur und Bischof blieben bis zum Tod des letzteren am 19.4.1612 in Vic gespannt ${ }^{170}$, und das Hochstift Metz behielt trotz des vermehrten Drucks seine nominelle Unabhängigkeit. Nach Givrys Tod übernahmen aufgrund der Minderjährigkeit des designierten Bischofs Henri de Bourbon zunächst sechs Mitglieder des Domkapitels die Verwaltung von Bistum und Territorium ${ }^{171}$. Mit den Kanonikern glaubte der Gouverneur Épernon ein leichteres Spiel zu haben. Im Jahr 1613 versuchte er erneut, die Anerkennung des königlichen Patents von $1609 \mathrm{zu}$ erreichen, doch auch die Beamten des Hochstifts pochten auf ihre Unabhängigkeit: Sie weigerten sich, Épernon überhaupt erst zu Gesprächen in Metz aufzusuchen ${ }^{172}$.

Das Metzer Domkapitel, immer noch bedrängt, den Treueid zu leisten, informierte statt dessen im Reich Kaiser Matthias über Jean-Louis Épernons Pläne. Der schickte sofort einen Gesandten, Graf Johann Georg von Hohenzollern, doch als dieser im März im Hochstift Metz eintraf, konnte er nur noch gegen vollendete Tatsachen protestieren - die Verwalter hatten den Treueid im Januar 1614 bereits leisten müssen ${ }^{173}$. Auf dem Ständetag des Hochstifts erreichte der Gesandte allerdings von den Abgesandten der drei Stände einen

\footnotetext{
${ }^{167}$ HAMMERSTEIN, Der Metzer Bischof, S. 155 und FOLZ, Concordat, S. 125.

${ }^{168}$ Zitat und Schilderung nach HAMMERSTEIN, Der Metzer Bischof, S. 159.

${ }^{169}$ Ibid. S. 160 und $167-170$.

${ }^{170}$ Cabourdin, Histoire de la Lorraine, Bd. 3,1, S. 157.

${ }^{171}$ FoLZ, Concordat, S. 129.

${ }^{172}$ Die Lettres des Königs zur Ausdehnung des Gouvernements von Épernon von Oktober 1613 in BnF, Dupuy 334, fol. 113f. Zur Reaktion der Beamten: ZELlER, Réunion, Bd. 2, Anhang, Dokument 26.

${ }^{173}$ Der Text dieses Eides ist abgedruckt bei ZELLER, ibid. Anhang, Dokument 27.
} 
Widerruf des Treueids und die Zusage, auf keinen Fall die Stationierung französischer Truppen im bischöflichen Gebiet zuzulassen ${ }^{174}$. Die innenpolitisch schwierige Situation Frankreichs erleichterte Hohenzollerns anschließende Mission in Paris. Die Regentin und ihr Minister erklärten den Treueid für null und nichtig und der kaiserliche Abgesandte erhielt nun auch von französischer Seite die Zusage, daß keine Truppen in bischöfliches Gebiet gelegt würden ${ }^{175}$.

An einen verstärkten Einfluß des président im Hochstift Metz war unter diesen Bedingungen kaum noch zu denken, doch ebenso wie in der Stadt Metz, in Toul und Verdun setzte nun auch im Hochstift eine rege theoretische Beschäftigung mit der Verwaltung und vor allem mit der Gerichtsbarkeit der TroisÉvêchés ein. Noch eifriger als bisher wurde nach Beweisen für die Rechte des Königs wie des Bischofs gesucht. So wurde etwa 1607 eine sorgfältig recherchierte Denkschrift, offenbar als eine Art Landesbeschreibung für den neuen Bischof Anne de Givry, angefertigt ${ }^{176}$. Ein ähnliches Dokument ist auf den Januar 1608 datiert ${ }^{177}$. Etwa aus der gleichen Zeit stammt eine Denkschrift des procureur du roi in Metz Pierre Joly, die das Reichskammergericht mit scharfsinnigen Argumenten angreift ${ }^{178}$. 1609 fertigte der bischöfliche bailli Jean de Saintignon aus Verdun eine Zusammenstellung von Dokumenten zur Begründung der Souveränitätsrechte des Königs an ${ }^{179}$, etwa zum gleichen Zeitpunkt ließ der französische König in Toul nach möglichen Rechtstiteln suchen ${ }^{180}$. 1613 prüfte eine Abhandlung, welche Rechte der Status des protecteur dem König im Gebiet des Hochstifts Metz einbringe ${ }^{181}$.

\section{Militär und Zivilverwaltung Konflikte um den Gouverneur Épernon}

Der erneute, relative Rückzug der königlichen Machtinteressen aus den TroisÉvêchés nach dem Tod Heinrichs IV. hatte einen Grund in der Rolle des Metzer Gouverneurs in der Innenpolitik des Königsreiches. Jean-Louis de Nogaret de la Valette, Herzog von Épernon, war ein persönlicher Freund Heinrichs III.

\footnotetext{
${ }^{174}$ Ibid. S. 228-230.

${ }^{175} \mathrm{Zu}$ Hohenzollerns Mission: CABOURDIN, Histoire de la Lorraine, Bd. 3,1, S. 158.

${ }^{176} \mathrm{BnF}$, Dupuy 334, fol. 5-13.

${ }^{177}$ Ibid. fol. 15-24.

${ }^{178}$ BnF, Dupuy 53, fol. 14-21.

${ }^{179}$ Institut, Godefroy 265, fol. 24-27.

${ }^{180} \mathrm{Vgl}$. RouX, in: Position des thèses, S. 79.

${ }^{181} \mathrm{BnF}$, Dupuy 334, fol. 64-68.
} 
und Heinrichs IV. und hatte es stets verstanden, trotz seines schwierigen Charakters $^{182}$ unzählige Getreue um sich zu sammeln. Seit 1583 war er Gouverneur in Metz und sollte dieses Amt, das er ab 1609 zusammen mit seinem Sohn Bernard de la Valette ausübte, über 50 Jahre behalten. Er war jedoch genausowenig wie seine Vorgänger über längere Zeit in der Moselstadt anwesend - insgesamt nur zehnmal - denn Metz war weit entfernt vom Hof ${ }^{183}$. Épernons ursprüngliches Gouvernement von Toul und Verdun hatte sich in den Religionskriegen nicht halten lassen. Seit April 1585 waren beide Städte von Truppen der Liga besetzt, und nach dem Frieden waren sie dem Herzog von Vaudemont, einem Sohn des lothringischen Herzogs, zugefallen. Dort wurden die sogenannten lieutenants-généraux zu den eigentlichen militärischen Repräsentanten des Königs. Während nach 1585 die Gouvernements von Toul und Verdun von dem von Metz getrennt blieben, amtierte seit 1607 mit François de Montigny nur noch ein Statthalter für Metz, Toul und Verdun $^{184}$.

Doch trotz seiner häufigen Abwesenheit und seinem faktischen Machtverlust in Toul und Verdun behielt Jean-Louis d'Épernon einen kaum zu unterschätzenden Einfluß in den Trois-Évêchés. Seine Position innerhalb des französischen Adels und bei Hofe, die sein Biograph Jean-Luc Chartier als presque-roi bezeichnet hat ${ }^{185}$, ermöglichte es ihm, Verwandte und Freunde auf Schlüsselpositionen in den Trois-Évêchés zu plazieren. So waren seine Stellvertreter in Metz, die lieutenants Termes, Saint-Colombe und Moncassin seine direkten Vertrauten. Hinzu kam, daß Épernons Familienangehörige Benefizien in Metz und Umgebung erwarben, beispielsweise war seine uneheliche Tochter Äbtissin von Sainte-Glossinde in Metz, sein Sohn Kardinal Louis de La Valette hielt zwei Metzer Benediktinerabteien als Kommende ${ }^{186}$.

Bei Hofe begann Jean-Louis d'Épernons Position im Jahr 1618 mit dem Befreiungsschlag Ludwigs XIII. gegen seine Mutter und ihrem Vertrauten den Marschall Concino Concini an Bedeutung zu verlieren. Die Festnahme und Hinrichtung Concinis führte zum unfreiwilligen »Exil« der Königinmutter in Blois ${ }^{187}$. Épernon schloß sich der Partei der Königinmutter an und verließ im Mai 1618 demonstrativ den Hof, um sich nach Metz zurückzuziehen und sich

${ }^{182}$ Yves-Marie BERCE, La naissance dramatique de l'absolutisme 1598-1661, Paris 1992, S. 55. Zu Épernons Aufstieg vgl. auch Maria CHAINTRON, Le duc d'Épernon (1554-1642). L'ascension prodigieuse d'un cadet de Gascogne, Paris 1988.

${ }^{183}$ ZELLER, Réunion, Bd. 2, S. 88.

${ }^{184}$ Ibid. S. 91.

${ }^{185}$ Jean-Luc ChartiER, Le duc d'Épernon, 2 Bde., Paris 1999.

${ }^{186}$ LE MOIGNE in: PARISSe (Hg.), Lothringen - Geschichte eines Grenzlandes, S. 300.

${ }^{187}$ Die Ereignisse sind ausführlich geschildert bei Roland MOUSNIER, L'homme rouge ou la vie du Cardinal de Richelieu (1585-1642), Paris 1992, S. 139-189. 
dort regelrecht zu verschanzen ${ }^{188}$. Gleich nach seiner Ankunft setzte er einen neuen Magistrat ein. Der als königstreu bekannte Metzer Schöffenmeister Nicolas Maguin mußte Abraham Fabert, einem Parteigänger Épernons, weichen ${ }^{189}$. Gleichzeitig war das zweite wichtige königliche Amt neben dem Gouverneur, das des président, seit 1617 vakant. Während Épernon selbst Metz schon bald wieder verließ, setzte sein Sohn, Bernard de La Valette, die Moselstadt in einen Belagerungszustand. Die Tore wurden geschlossen und alle Bürger entwaffnet ${ }^{190}$. Damit war Metz praktisch nicht mehr in königlicher Hand. Zwei maîtres des requêtes wurden zur Wiederherstellung der Ordnung abgesandt, doch jedesmal war bereits kurz nach ihrer Abreise aus Metz wieder der Belagerungszustand hergestellt. Erst der plötzliche Tod von Charles d'Albert de Luynes, Épernons entschiedener Gegner bei Hofe, im Jahr 1621 konnte eine Beruhigung der Situation bewirken ${ }^{191}$.

Es ist kaum verwunderlich, daß Jean-Louis d'Épernons Verhalten zahlreiche Kritiker auf den Plan rief. In Metz hatten die Vorwürfe gegen den Gouverneur einen scharfen Ton angenommen, wie ein Pamphlet mit dem Titel Descharge de conscience de Marel zeigt, in dem Épernon sein Versagen beim Versuch, einen Treueid im Hochstift Metz zu erlangen, vorgeworfen wird. Ausdrücklich ist daneben auch von seiner Tyrannei und Ungerechtigkeit die Rede ${ }^{192}$. Eine Quelle der Unzufriedenheit war hierbei die Militärjustiz: 1619 mußte der (mit Rechtstitel des Intendanten) kommissarisch eingesetzte président Guillaume de Marescot ein gutes Dutzend Bürger freilassen, die von Épernons Militärrichter, dem prévôt des maréchaux, willkürlich verhaftet worden waren ${ }^{193}$.

Der dringende Bedarf eines président in Metz war jedoch nicht nur durch die innenpolitische Brisanz von Épernons »Alleinherrschaft « deutlich geworden. Die Bürger von Metz belegten einen entsprechenden Bedarf auf dem Rechtsweg: Immer mehr Gerichtsverfahren wurden in den Jahren um 1620 zur Überprüfung vor das Parlament von Paris und den conseil du roi getragen, nicht selten mit sehr deutlichem Hinweis auf fehlende Kontrollmöglichkeiten in Metz selbst ${ }^{194}$.

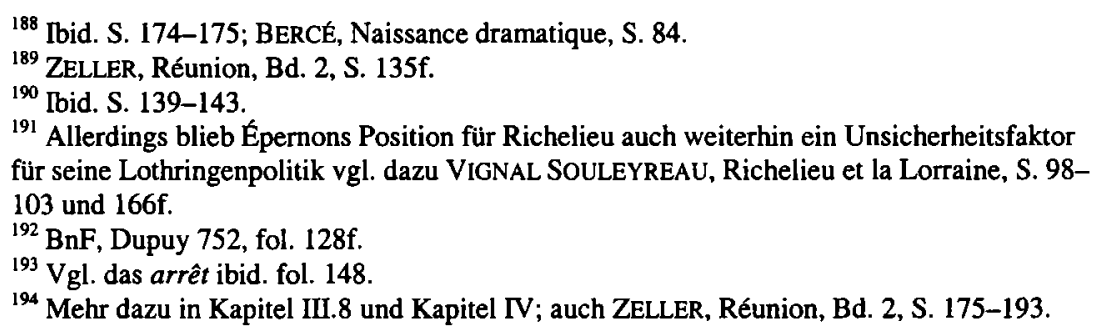




\section{Die Kommission von Cardin Le Bret im Jahr 1625}

Die gegen Ende des Jahres 1624 eingesetzte Kommission unter Cardin Le Bret bedeutete einen weiteren Vorstoß der französischen Krone zur Eingliederung der Trois-Évêchés. Dieser Schritt wird meist auch mit dem Wiedereintritt und der Übernahme einer leitenden Funktion des Kardinal Richelieu im Staatsrat in Verbindung gebracht ${ }^{195}$. Hinzu kam der nach dem Tode des lothringischen Herzogs Henri II immer offener zutage tretende Konflikt zwischen der französischen Krone und dem neuen, umstrittenen Herzog Charles IV, sowie die durch Lehnsstreitigkeiten um die Herrschaft Malatour erneut drängende Frage nach Herrschaftsrechten und Lehnshoheiten im lothringischen Raum ${ }^{196}$.

Der Auftrag an die nach Metz, Toul und Verdun entsandten Kommissare war vor allem, les usurpations et acquisitions faites par des étrangers aufzuklären, d.h. Verlehnungen bischöflicher Besitzungen vor allem an den Herzog von Lothringen aufzulisten und möglichst auch abzustellen ${ }^{197}$.

Hiermit sollte der königliche Einflußbereich im Prinzip auf die gesamte lothringische Region ausgedehnt werden. Die Tendenz zur juristischen Untermauerung von Herrschaftsansprüchen bestand jedoch, wie oben betont, schon seit der Regierungszeit Heinrichs IV. Welche Bedeutung die Kommission von 1624 für die theoretische Entwicklung und historische Untermauerung eines königlichen Anspruches auf "Souveränität« hatte, soll an späterer Stelle noch einmal beleuchtet werden. Hierbei wird sich zeigen, daß sie weit mehr als nur ein Vorläufer der sogenannten Reunionskammer von 1679 war, wie dies ein Großteil der Literatur darstellt ${ }^{198}$. Zunächst soll in diesem Abschnitt jedoch die konkrete Funktion für die Entwicklung der königlichen Position vor Ort im Vordergnund stehen.

Die Kommission von 1624 bestand aus Persönlichkeiten, die für die Ausprägung der Souveränitätslehre, für die Legitimierung der königlichen Expansionspolitik und für das Bild der réunion in der Geschichtsschreibung von großer Bedeutung bleiben sollten. Cardin Le Bret, Kronanwalt am Parlament von Paris, war ein Vertrauter des Königs und hatte schon damals den Ruf ei-

${ }^{195}$ So bei ZELLER, Réunion, Bd. 2, S. 232; auch kürzlich THÉBAUT, La question, S. 37; vorsichtiger MOUSNIER, L'homme rouge, S. 425 und 515-518, und STEIN, Protection, S. 79-86.

${ }^{196}$ Vignal SOULEYREAU, Richelieu et la Lorraine, S. 86f.

${ }^{197}$ Zitiert nach CABOURDIN, Histoire de la Lorraine, Bd. 3,1, S. 182.

198 So bei Marie-Odile PIQUET-MARCHAL, La chambre de réunion à Metz, Paris 1969 (Travaux et recherches de la faculté de droit et des sciences économiques à Paris. Série »sciences historiques«, 17), S. 29-33; CABOURDIN, Histoire de la Lorraine, Bd. 3,1, S. 181 und KAUFMANN, Reunionskammer, S. 35, der die Kommission gar als eine "Vorreunionskammer« bezeichnet. 
nes berulhmten Juristen ${ }^{199}$. Als Leiter der Kommission wurde er zum Intendanten der Trois-Évêchés ernannt ${ }^{200}$. Jean Delon, Sieur Delorme, Schatzmeister in der Generalität von Châlons ${ }^{201}$, und Pierre Dupuy, der sich bereits durch die Inventarisierung des Kronarchivs profiliert hatte ${ }^{202}$, begleiteten Le Bret. Vor Ort stieß Michel Charpentier, seit 1621 als président in Metz, zu den Kommissaren $^{203}$.

Der Auftrag war ausgesprochen weit gefaßt: Die Kommissare sollten zunächst allen Bischöfen, Kanonikern, Magistraten und Bewohnern der drei Hochstifte mitteilen, daß sie im Auftrag des Königs handelten. Sie seien dazu abgesandt, genau zu beobachten, wie die Territorien regiert würden und wie Recht gesprochen würde, um bei eventuellem Anlaß zur Klage sogleich Abhilfe leisten zu können. Verbunden sein sollte dies mit der Ankündigung, daß sich der König in Zukunft stärker mit diesen Gebieten befassen wolle ${ }^{204}$. Im Vordergrund stand hierbei die Aufgabe, die Verlehnungen von bischöflichem Gebiet zu dokumentieren und für die Zukunft zu untersagen. Hierzu sollten Karten angefertigt werden, die die Trois-Évêchés in den Grenzen von 1552 zeigten.

Doch ein genauso wichtiger Punkt waren Fragen der Gerichtsbarkeit: Im Auftrag war bestimmt worden, daß die Kommissare die Appellationen nach Speyer ausdrücklich verbieten und statt dessen die Anerkennung des président royal als obersten Richter durchsetzen sollten ${ }^{205}$. Die bischöflichen und lehnsherrlichen Gerichte sollten in Zukunft nicht mehr in letzter Instanz urteilen können, ausgenommen bei Zivilsachen von einem Streitwert unter 250 Pfund. Auch in Strafsachen, bei denen peinliche Strafen, Ehrenstrafen oder Verbannung verhängt wurden, sollte nun eine Appellation möglich sein ${ }^{206}$. Weiterhin sollten die Kommissare dafür sorgen, daß sämtliche cas royaux - das heißt Straftaten wie Majestätsbeleidigung, Gotteslästerung, Falschmünzerei etc. ${ }^{207}$

${ }^{199}$ Vgl. zu Le Brets Biographie: Gilbert PICOT, Cardin Le Bret (1558-1655) et la doctrine de la souveraineté. Nancy 1948, hier S. 45.

${ }^{200}$ PICOT, Cardin Le Bret, S. $45 f$.

${ }^{201}$ PIQUET-MARChal, Chambre de Réunion, S. 30.

${ }^{202}$ RomAN D'AMAT, in: Dictionnaire de Biographie Française, Bd. 12, Paris 1970, Sp. $596 f$.

${ }^{203}$ Charpentier wurde bereis 1620 ernannt, Selve amtierte aber noch bis Februar 1621, vgl. ZELLER, Réunion, Bd. 2, S. 188.

${ }^{204}$ Institut, Godefroy 336, fol. 139-142. Der Auftrag ist gedruckt bei PIQUET-MARCHAL, Chambre de Réunion, S. 127-129.

${ }^{205}$ Instructions... 13.11.1624, abgedruckt ibid. Annexe VI:C, S. 127.

${ }^{206}$ Instructions... 13.11.1624, ibid. S. 128.

${ }^{207}$ Was genau zu den cas royaux gehörte, wurde erst durch die Ordonnanz von 1670 aufgrund der älteren Gewohnheit festgelegt. Nach der heutigen Strafrechtslehre würde man die meisten der dort aufgezählten Tatbestände als Verbrechen gegen Rechtsgüter der Allgemeinheit qualifizieren. Bemerkenswert ist, daB auch viele klassische Zuständigkeitsbereiche 
ebenfalls ausschließlich vor den Präsidenten in Metz als Vertreter der Krone gebracht würden ${ }^{208}$.

Vorsorglich lieferte der Auftrag aus Paris den Kommissaren gleich die nötigen Argumente mit, um bei einem möglichen Widerstand gegen die Regelungen zur Gerichtsbarkeit Überzeugungsarbeit leisten zu können. So sollte man den bischöflichen Beamten vor Augen halten, daß der neue Appellationsstreitwert für die Gerichtsbarkeit des président royal viel höher sei, als der des Reichskammergerichtes $^{209}$. Dazu kam das Argument, daß die BailliageGerichte nun zusätzlich für kleinere Strafsachen in letzter Instanz zuständig sein sollten, was ihnen im Gegensatz zur früheren ausschließlichen Zuständigkeit bei Prozessen gegen straffällig gewordene Vagabunden höhere Einnahmen durch Beschlagnahme von Gütern der Verurteilten verspreche ${ }^{210}$.

$\mathrm{Da}$ die Gerichtsbarkeit des président für all diese angestrebten Zuständigkeiten aber auf Dauer nicht die richtige Institution sein könnte, war in Paris klar, denn der Plan eines Parlaments oder einer ähnlichen Institution existierte bereits ${ }^{211}$ : Die Kommissare sollten deshalb auch herausfinden, ob es möglich sei, einen obersten Gerichtshof (chambre souveraine) in Metz einzusetzen, der zur Hälfte aus Bewohnern des Königreiches, zur Hälfte aus denen der drei Bistumer zusammengesetzt sei. Interessant ist hierbei, daß die Kommissare ausdricklich angewiesen wurden, l'advis des principaux desdits villes et pays einzuholen. Falls sie zu der Meinung gelangen sollten, daß ein solcher Gerichtshof nicht zu realisieren sei, sollten sie wenigstens versuchen, die Bürger

der geistlichen Gerichte, wie Gotteslästerung, heimliche Heirat und Ehebruch zu den cas royaux gezählt wurden, vgl. CABOURDIN, Lexique, S. 51.

${ }^{208}$ Instructions... 13.11.1624, abgedruckt bei PIQUET-MARCHAL, Chambre de Réunion, Annexe VI:C, S. 127.

${ }^{209}$ Die Appellationssummen waren in unterschiedlichen Währungen berechnet, die jedoch beide die relativ kleine Münzeinheit des denier gemeinsam hatten: 250 Pfund entsprachen 60000 deniers, die Appellationssumme des Reichskammergerichts, 150 Francs barrois, entsprachen etwa 28000 deniers. Die neue Appellationssumme war also etwa doppelt so hoch wie die des Reichskammergerichtes. Berechnung nach der Tabelle bei CABOURDIN, Histoire de la Lorraine, Bd. 3,1, S. 21.

${ }^{210}$ Instructions... 13.11.1624, abgedruckt bei PIQUET-MARCHAL, Chambre de Réunion, Annexe VI:C, S. 128.

${ }^{211}$ Die erste Anregung zu einem solchen Gerichtshof für die besetzten Gebiete kam wohl aus Verdun: Dort hatte man noch bis zur Jahrhundertwende die Appellationen nach Speyer gebracht, und forderte 1606, offenbar auf eine Initiative des dortigen königlichen Vertreters la Plume, eine chambre royale, die das Reichskammergericht als Appellationsinstanz ersetzen solle (vgl. ZELLER, Réunion, Bd. 2, S. 270f.). Bei ZELLER, ibid. S. 270-273 auch weitere Angaben über einzelne Pläne oder Ideen zur Errichtung eines souveränen Gerichtshofes oder Parlaments in den drei Bistümern. 
dazu zu bewegen, das Parlament von Paris als oberste Appellationsinstanz anzuerkennen ${ }^{212}$.

Die erste Etappe der Kommissare war Toul. Dort trafen sie am 25. April $1625 \mathrm{ein}^{213}$. Das Vorgehen war überall gleich ${ }^{214}:$ Zunächst erbaten Le Bret und seine Mitarbeiter einen Bericht des örtlichen procureur général zu den Angriffen auf das »Protektionsrecht«, wie es in den Dokumenten bezeichnet wird. Danach folgte eine Untersuchung der Kommissare, die meist auf die bereits vorbereiteten Dokumentationen der procureurs zurïckgreifen konnten, dann Archivrecherchen und die Anhörung von Zeugen. Schließlich wurde eine Ordonnanz zum Ausmaß der Usurpationen und mit dem Verbot weiterer Verlehnungen veröffentlicht. Weiterhin wurden erneut die bereits bestehenden Regelungen zur Gerichtsbarkeit bestätigt, interpretiert und ausgeweitet.

Während die procureurs in Toul und Verdun vor allem territoriale Usurpationen der Herzöge von Lothringen zu beklagen hatten, stand bei der Stellungnahme zum Hochstift Metz die Gerichtsbarkeit im Vordergrund. Besonderen Anlaß zur Klage gaben die Berufungen aus dem Hochstift nach Speyer. Sowohl im königlichen Auftrag als auch im späteren Bericht der Kommissare wurden die Schwierigkeiten, die für die Rechtssuchenden mit einer Appellation nach Speyer verbunden waren, angesprochen. So berichteten die Kommissare des Königs von großer Unzufriedenheit mit dieser Institution unter der Einwohnerschaft: Die Bewohner würden, »wenn es ihnen erlaubt wäre, in ganzen Scharen kommen, um sich zu beschweren und zu beklagen, daß sie gezwungen sind, ihrem Recht zu entsagen und sechs lange Tagesreisen von ihrem Wohnsitz entfernt Gerechtigkeit zu suchen, und so lange Prozesse auf sich nehmen müssen, daß es ein ganzes Menschenleben braucht, um das Ende zu erleben. Hinzu kommen weitere Unannehmlichkeiten wie der Sprachunterschied zum Deutschen, das ihnen unbekannt ist, so daß sie gezwungen sind, sich ihre Prozesse übersetzen zu lassen und immer einen Übersetzer bei sich zu haben ${ }^{215}$.

Während ihrer Tätigkeit in Metz haben die Kommissare weiter nach Argumentationsmaterial für die Begründung einer Appellationsmöglichkeit vom

${ }^{212}$ Vgl. den genauen Wortlaut des Auftrages bei PIQUET-MARCHAL, Chambre de Réunion, Annexe VI:C, S. 128.

${ }^{213} \mathrm{Vgl}$. den Bericht des Demange Bussy, BnF, N.a.fr. 22622, fol. 45v.

${ }^{214}$ ZELLER, Réunion, Bd. 2, S. 233.

${ }^{215}$ Übersetzung der Autorin: ...s'il leur était permis, viendraient en troupes pour s'en plaindre, et remonstrer qu'ils sont contraints de renoncer à leurs droits plutost que d'aller rechercher la justice à six grandes journées de leurs domiciles et avec tant de longueurs qu'il faut la vie d'un homme pour en voir le bout, joint les autres incommoditez, à cause de la diversité de la langue qui leur est inconnue, estant à cette occasion contraints de faire translater leurs procès en langue germanique et d'avoir tousjours avec eux un truchement pour parler à leurs juges, procureurs, advocats et greffiers... abgedruckt bei PIQUET-MARCHAL, Chambre de Réunion, Annexe VI:D, S. 130. 
Bailliage-Gericht in Vic vor dem président royal in Metz gesucht. Während ihnen das bischöfliche Archiv verschlossen blieb, fiel ihnen die Urteilssammlung des Metzer Schöffenmeisters aus der ersten Hälfte des 16. Jahrhunderts in die Hände, in der auch Berufungen von den bischöflichen Gerichten zu finden waren. Dies sei ein eindeutiger Beweis dafür, daß Hochstift und Stadt ein einziges Territorium (un même pays) seien, und daß der Schöffenmeister und der président als dessen Rechtsnachfolger die eigentlichen, angestammten Appellationsrichter für die Gerichte des Hochstiftes seien ${ }^{216}$.

Die in den Trois-Évêchés gesammelten Dokumente wurden 1626 dem conseil du roi vorgelegt, blieben zunächst aber vollkommen folgenlos. Im Gegenteil, Cardin Le Bret schien beim Kardinal Richelieu regelrecht in Ungnade gefallen zu sein ${ }^{217}$. Dies lag daran, daß der Jurist in seinem Eifer weit über das Ziel hinausgeschossen war und die sogenannten arrets de réunion, die die Kommission bezüglich der angeblichen oder tatsächlichen Usurpationen vor allem des lothringischen Herzogs erlassen hatte, eine vitale Bedrohung für das Herzogtum darstellten. Hätte man sie wirklich durchsetzen wollen, wäre der herzoglich-lothringische Staat »in einschneidenster Weise amputiert« worden, wie es Rainer Babel betont ${ }^{218}$.

Die Beziehungen der Krone zum neuen lothringischen Herzog Charles IV hatten sich so dramatisch verschlechtert ${ }^{219}$, daß man einen Rückzieher machte: als Charles IV eine Konferenz uber strittige Rechtsfragen ablehnte, wurde ihm königlicherseits angedeutet, die Ergebnisse der Kommission hätten keinen Rechtscharakter, sondern seien vielmehr als Bestandsaufnahme zu werten ${ }^{220}$. Auch in den Memoiren Richelieus wird berichtet, die Urteile Le Brets seien aus Rücksicht auf die Interessen des lothringischen Herzogs widerrufen worden. Interessant ist hierbei die Formulierung, die die Ansprüche des Herzogs berücksichtigt, ihm aber trotzdem weiterhin usurpation unterstellt: On a fait révoquer les jugements du Sieur Le Bret qui adjugeoient au Roi beaucoup des terres que le duc de Lorraine avait usurpées et qu'il possédait comme appartenant à son duché2 $e^{221}$.

${ }^{216}$ Inventaire des titres... Juni 1625, ibid. Annexe VI:E, S. 136.

${ }^{217} \mathrm{Vgl}$. THÉBAUT, La question, S. 41, 45.

${ }^{218}$ BABEL, Zwischen Habsburg, S. 48. Ähnlich auch Vignal SOULEYREAU, Richelieu et la Lorraine, S. 90-92.

${ }^{219}$ Eine umfassende Analyse der außenpolitischen Position Herzog Charles IV, aber auch seiner Persönlichkeit bietet BABEL, Zwischen Habsburg.

${ }^{220}$ Ibid. S. 51.

${ }^{221}$ Zitiert nach THÉBAUT, La question, S. 45. 


\section{Die Ereignisse nach 1625}

Das Vorgehen der Kommission hatte zwar eine Bestandsaufnahme gebracht, aber an den tatsächlichen Verhältnissen nur wenig geändert. Während sich das Herzogtum Lothringen zunehmend zu einem Sammelbecken für all jene entwickelte, die mit der königlichen Politik unzufrieden waren ${ }^{222}$, beharrte der Metzer Gouverneur auch nach 1621 auf seinen Unabhängigkeitsbestrebungen. So setzte ein besorgtes Mitglied der Metzer Dreizehn den Hof darüber in Kenntnis, wie die Wahl der städtischen Amtsträger in Metz im Jahr 1626 abgelaufen war und mit welchen Mitteln der Gouverneur seine Vorauswahl unter den Kandidaten getroffen und diese dann auch durchgesetzt hatte ${ }^{223}$. Noch kritischer setzte sich der anonyme Autor einer nach 1619 entstandenen Denkschrift mit dem Gouvernement Épernons auseinander. Er betonte nicht nur seine fast gänzlich unabhängige Position, sondern zeigte auch auf, welche Folgen dieses Regiment für die Gerichtsbarkeit in Metz hatte: Zahlreiche ungesühnte Morde, Willkür und Tyrannei seien zu beobachten ${ }^{224}$. Auch die Ständeversammlung der Stadt Metz beschwerte sich beim König über Épernons Militärherrschaft: 1627 beklagte sie, daß sich viele Bürger der städtischen Gerichtsbarkeit und den Steuerforderungen durch Eintritt in die Garnison entzögen ${ }^{225}$.

In Toul begann Louis Gillot, Vertreter des président am dortigen königlichen Gericht, seine Kompetenzen im Namen des Königs immer weiter auszulegen: Bischof Nicolas François, ein Bruder des lothringischen Herzogs, beschwerte sich 1627 bei Richelieu, daß Gillot eigenmächtig den Touler Schöffenmeister eingesetzt habe ${ }^{226}$. Noch war diese Klage ein Einzelfall, doch weitere Beschwerden über Gillot sollten folgen.

Zum gleichen Zeitpunkt entspann sich in Verdun ein folgenreicher Konflikt zwischen dem herzogstreuen Bischof François de Lorraine und dem dortigen königlichen Gouverneur Louis de Marillac. Schon 1623 hatte sich der Bischof unter den Schutz des Herzogs von Lothringen gestellt. Die französische Antwort darauf war der Bau einer Zitadelle, die seit 1625 unter Marillac als neuem Gouverneur entstand. Die damit verbundenen Forderungen an die Bevölkerung und Zerstörungen, darunter die einer ganzen Vorstadt, trugen noch weiter zur frankreichfeindlichen Stimmung des Bischofs bei. Hinzu kam die Verärgerung über die Maßnahmen Le Brets: Dieser hatte nicht nur die Usurpa-

\footnotetext{
${ }^{222}$ VIGNAL SOULEYREAU, Richelieu et la Lorraine, S. 98-104.

${ }^{223}$ Flavigny an d'Herbault, 3.12.1626, AMAE, CP Lorr. 8, fol. 69.

${ }^{224} \mathrm{BnF}$, Dupuy 752, fol. 173-178.

${ }^{225}$ BnF, N.a.fr. 22668, fol. 52-56.

${ }^{226}$ AMAE, CP Lorr. 8, fol. 117.
} 
tionen von bischöflichem Gebiet erforscht, sondern sich auch in die Verwaltung des Hochstifts eingemischt. So hatte er in seiner Ordonnanz von 1625 den procureur du roi in Verdun ermächtigt, in allen kleineren Zivilsachen sowie als Vertreter des président in allen Appellationssachen zu urteilen. Auch Polizeiverfahren waren nun nicht mehr allein Sache des Verduner Magistrats, sondern wurden zusammen mit dem Gouverneur geregelt ${ }^{227}$. Auslöser für den endguiltigen Bruch war dann die Zerstörung einer Kirche und Beschlagnahmung einiger Gebäude der Abtei Saint-Vanne für den Bau der Zitadelle durch den Gouverneur, die den Bischof im Dezember 1626 veranlaßte, Plakate anschlagen zu lassen, die all jene mit Exkommunikation bedrohten, die Hand an Kirchengüter legten ${ }^{228}$. Damit hatte der Bischof seinen Untertanen quasi jede Mitarbeit an der Zitadelle untersagt. Als der Verduner procureur du roi Jean Gillet diese Plakate wieder abreißen ließ, wurde er exkommuniziert. Bischof François rechtfertigte sich beim König für sein Handeln und ging sogar so weit, diesem Wortbrüchigkeit vorzuwerfen ${ }^{229}$.

Damit war der offene Bruch vollzogen: Am 8. Februar 1627 ließ der président das Exkommunikationsschreiben des Bischofs von Verdun öffentlich verbrennen und verurteilte diesen zu 10000 Francs Geldstrafe oder Gefängnis $^{230}$. Doch François de Lorraine weilte nicht mehr im Einflußbereich der königlichen Justiz: Er war nach Köln geflüchtet ${ }^{231}$. Letztlich hatte er damit jedoch nur der französischen Politik Vorschub geleistet. Seine Einkünfte wurden eingezogen, seine Amtsträger entlassen, und der Magistrat der Stadt aufgelöst - freies Feld für die hommes $d u r^{20 i^{232}}$. In Verdun wurde eine städtische Kommission eingerichtet, die dem König gegen Bestätigung der Magistratsprivilegien anbot, sujets $d u$ roi zu werden ${ }^{233}$. Ähnliche Interessen finden sich auch in den Denkschriften des Adels und der Bürger von Verdun. Auch sie boten, ähnlich wie der Magistrat, ihre Unterwerfung unter die Krone gegen Bestätigung oder sogar Ausweitung ihrer Privilegien und Befriedigung ihrer materiellen Interessen (vor allem freier Handel mit dem Königreich) $a^{234}$. Das $\gg G e-$ schäft« hatte Erfolg: Am 23. März 1627 bestätigte der König alle gewünschten Privilegien und konnte die Bewohner von Verdun nun als vrais et naturels

${ }^{227}$ LE MOIGNE in: GIRARDET (Hg.), Histoire de Verdun, S. 144.

${ }^{228}$ CABOURDIN, Histoire de Lorraine, Bd. 3,1, S. 183.

${ }^{229}$ AMAE, CP Lorr. 8, fol. 87.

${ }^{230}$ PETITOT-BELLAVÈNE, Deux siècles, S. 274.

${ }^{231}$ LE MOIGNE in: GIRARDET (Hg.), Histoire de Verdun, S. 144.

${ }^{232}$ Ibid. Der Ausdruck hommes du roi ebenfalls bei Le Moigne in seinem gleichnamigen Aufsatz, François-Yves LE MOIGNE, »Hommes du Roi« et pouvoir municipal à Metz 16411789, in: DERS., La Lorraine, passionnément. Pages d'histoire XVIr $-\mathrm{XIX}^{e}$ siècles, Metz 1993, S. 9-37. Die Dokumente finden sich in BnF, Cinq-Cents Colbert 440 und A.C. Verdun, AA 2.

${ }^{233}$ PetiTot-Bellavìne, Deux siècles, S. $275 \mathrm{f}$.

${ }^{234}$ Die Dokumente finden sich in BnF, Cinq-Cents Colbert 440 und A.C. Verdun, AA 2. 
François bezeichnen ${ }^{235}$. Weiterhin ernannte er einen neuen doyen séculier und einen neuen Schöffenmeister, ließ die Arbeiten an der Zitadelle forcieren und ersetzte überall in der Stadt die Reichswappen und -embleme durch Lilien ${ }^{236}$.

Auch als sich Bischof François de Lorraine im Jahr 1629 selbst dem König unterwarf und wieder als Bischof amtierte, änderte sich an der Situation nur wenig, denn seine Amtsträger mußten weiterhin einen Treueid auf den König leisten und dieser behielt sich die Ernennung des doyen vor $^{237}$. Doch immerhin verschwand François' Feind Marillac aus der Stadt - er geriet aufgrund der innenpolitischen Wirren am Königshof in Gefangenschaft ${ }^{238}$. Die Zitadelle, die von einem Parteigänger Marillacs verteidigt wurde, mußte allerdings mehrere Wochen belagert werden, bis der ehemalige Gouverneur persönlich aus der Gefangenschaft ihre Übergabe anordnete - ein erneuter Rückschlag für die königliche Autorität vor $\mathrm{Ort}^{239}$.

Während die Garnison in Verdun durch ihre Treue zum abgesetzten Gouverneur Marillac Probleme bereitete, tauchten kaiserliche Truppen im Hochstift Metz auf und bauten den kleinen Ort Moyenvic, direkt neben Vic-surSeille, dem Hauptverwaltungsort des Hochstift Metz gelegen, zur kaiserlichen Festung aus ${ }^{240}$. Der Dreißigjährige Krieg war in Lothringen angekommen. Im Herbst 1631 setzte Richelieu zum Gegenschlag an: Die Aktion war im Geheimen gut vorbereitet, denn die Truppen des lothringischen Herzogs Charles IV waren im Reich gebunden, und die kaiserliche Besatzung in Moyenvic war auf einen Angriff nicht gefaßt. Die kaiserliche Garnison in Moyenvic ergab sich am 27. Dezember 1631. Der König, der sich derweil in Verdun aufhielt, empfing den hastig zurückgekehrten Herzog von Lothringen. Charles IV mußte einem Vertrag zustimmen, in dem er unter anderem versicherte, keine Bündnisse mit den Feinden des Königs einzugehen. Gleichzeitig wurde eine königliche Garnison nach Moyenvic gelegt, und das Hochstift Metz von diesem Moment an der gleichen Behandlung unterzogen wie die drei Städte und die Hochstifte Toul und Verdun: Berufungen vor dem Reichskammergericht wurden untersagt und die Bevölkerung mußte durch Geldzahlungen die Garnison unterstützen. Der Sonderstatus des Hochstifts war damit beendet.

${ }^{235}$ Die Bestätigung der Privilegien findet sich in BnF, N.a.fr. 7101, fol. 408-411.

${ }^{236}$ Le MoIGne in: Girardot (Hg.), Histoire de Verdun, S. 144, Petitot-Bellavéne, Deux siècles, S. 280-281.

${ }^{237}$ Ibid. S. 286-290.

${ }^{238}$ Marillac wurde 1630 zusammen mit seinem Bruder, dem Großsiegelbewahrer Michel de Marillac, höchstwahrscheinlich wegen seiner Nähe zur Königinmutter der Prozeß gemacht. Vgl. zu den Ereignissen BERCÉ, Naissance dramatique, S. 135, sowie Pierre de VAISSIÈRE, Un grand procès sous Richelieu. L'affaire du maréchal de Marillac (1630-1632), Paris 1924.

${ }^{239}$ KIEFFER, Verdun, S. $27 \mathrm{f}$.

${ }^{240}$ CABOURDIN, Histoire de la Lorraine, Bd. 3,1, S. 184. 
Kurz vor Abschluß des Vertrages zwischen Charles IV und dem französischen König hatte jedoch der Bruder des Königs, Gaston d'Orléans heimlich die Schwester des lothringischen Herzogs geheiratet. Der Dispens dazu war vom Bischof von Toul, Nicolas-François de Lorraine, einem Bruder des Herzogs, erteilt worden ${ }^{241}$. Ein Konflikt zwischen dem König und dem Herzogshaus schien erneut unausweichlich, und durch ihre verwandtschaftliche Verknüpfung mit den Parteien waren auch die drei Bischöfe von diesem Konflikt betroffen.

Die persönliche Anwesenheit des französischen Königs um die Jahreswende 1631/32 war möglicherweise durch die Beobachtung der Lage vor Ort und durch die zahlreichen Berichte liber Probleme bei der Durchsetzung der königlichen Justiz auch ein Auslöser dafür, daß ein Projekt wieder aufgenommen wurde, das die Gerichtsbarkeit endgültig im königlichen Sinne regeln sollte: die Errichtung eines Parlaments.

Eine Denkschrift des procureur du roi in Metz, Nicolas Conrard, macht deutlich, warum das Gericht des président nicht geeignet war, die königlichen Souveränitätsansprüche durchzusetzen: Insbesondere aufgrund der häufigen Abwesenheit des président war dessen Gericht kaum noch als eine königliche Institution zu erkennen. Der Schöffenmeister führte den Vorsitz und kontrollierte die Verhandlungen - ein Blick in die Sentenzen des Présidial-Gerichtes belegt, daß hier Schöffenmeister und Dreizehn sogar meist ganz ohne einen Vertreter des Königs tagten ${ }^{242}$. Auch die Militärgerichtsbarkeit konnte der président nicht durchsetzen. Von der Garnison wurde er in keinem Fall als Richter anerkannt. Hinzu kam noch die mangelhafte Kontrolle úber das städtische Territorium im Umland von Metz, von dessen Seigneurialgerichten die Gerichtsbarkeit des président ebenfalls nicht anerkannt wurde ${ }^{243}$. Conrards Bericht blieb deshalb kein Einzelfall. In der Zeit von Herbst 1631 bis Frühjahr 1632 traf eine Vielzahl solcher Dokumente aus den Trois-Évêchés bei der königlichen Administration in Paris ein, die zumeist ein ähnlich düsteres Bild vom Stand der Dinge zeichneten.

Eine wichtige Rolle spielten vor allem die Berichte des im Dezember 1630 zum intendant de la justice et des finances ernannten Isaac de Juye, Sieur de Moricq, der insbesondere in Metz und in Verdun die königliche Justiz unter die Lupe nahm. In Metz vertrat der Intendant den abwesenden président Charpentier $^{244}$ und schickte danach eine scharfe Verurteilung von dessen Amtsführung nach Paris. Auch über die Kritik an Charpentier hinaus hatte der Inten-

\footnotetext{
${ }^{241}$ Ibid. S. 187.

${ }^{242}$ Leider sind nur wenige Sentenzen des président erhalten, nämlich die der Jahre 16271628 und 1630-1631, vgl. A.C. Metz, FF 185.

${ }^{243}$ AMAE, CP Lorr. 11, fol. 10-14.

${ }^{244}$ ZELLER, Réunion, Bd. 2, S. 287.
} 
dant wenig Erfreuliches aus Metz und Verdun zu berichten: Der lothringische Herzog habe sich auch in den Hochstiften zum Herrn uber toute la campagne gemacht, und nur noch die Städte seien eigentlich zum königlichen Einflußbereich zu rechnen. Allerdings seien auch dort die Anhänger des Königs rar und würden bedroht ${ }^{245}$.

Aus Toul kamen weitere schlechte Nachrichten: Daß der dortige Bischof aufgrund seiner Verwandtschaft mit dem lothringischen Herzogshaus an der Vertretung französischer Interessen kaum interessiert war, war hierbei nur ein Problem ${ }^{246}$. Hinzu kam, daß die Amtsträger des Königs selbst völlig zerstritten waren. So berichtete der Stellvertreter des Kronanwaltes in Toul dem königlichen Rat, sowohl sein Vorgesetzter als auch der Statthalter des président und einige weitere Amtsträger aus Toul im Herzen lorrains seien ${ }^{247}$. Tatsächlich sind von den solchermaßen Angegriffenen, dem procureur Jacques Vaulcher und dem lieutenant Louis Gillot, auch aus den folgenden Jahren zahlreiche wenig schmeichelhafte Charakterskizzen uberliefert ${ }^{248}$. So hatte Gillot den verurteilten Mörder Martin Cheresq in Maizières bei Toul zu seinem Stellvertreter gemacht und damit zahlreiche Unruhen unter der Bevölkerung der umliegenden Orte provoziert ${ }^{249}$. Meist traten sie in den Quellen jedoch eher als energische Interessenvertreter des Königs auf. Jacques Vaulcher war beispielsweise etwa zur gleichen Zeit eifrig für die Krone tätig und verfaßte eine detaillierte Beschreibung der Institutionen in Toul ${ }^{250}$. Auch der Gouverneur von Toul, Jacques Ligniville de Vannes, legte seine Analyse der Verhältnisse und seine weitreichenden Änderungsvorschläge (u.a. Absetzung des amtierenden, herzogstreuen Bischofs) dem König vor ${ }^{251}$.

Eine anonyme Denkschrift, die aufgrund des Überlieferungszusammenhanges in den gleichen Zeitraum zu datieren ist, beklagt, daß die Amtsträger des französischen Königs in Toul bedroht würden und derart eingeschüchtert seien, daß sie die Interessen des Königs nicht mehr vertreten könnten. Auch in diesem Dokument wird weiter deutlich gemacht, wie stark die alten Eliten in der Stadt noch immer mit dem Herzogtum verbunden waren und daß die Bevölkerung es unter solchen Bedingungen kaum wagte, sich offen zum König zu bekennen ${ }^{252}$.

${ }^{245}$ AMAE, CP Lorraine 10, fol. $20 f$.

246 Vgl. dazu die anonyme Denkschrift eines Klerikers aus Toul in AMAE, CP Lorr. 9 , fol. 333 .

${ }^{247} \mathrm{BnF}$, fr. 16890 , fol. $430-437$.

${ }^{248} \mathrm{Zu}$ Louis Gillot und den zahlreichen Beschwerden uber ihn mehr in Kapitel V.11.

${ }^{249}$ Vgl. AMAE, CP Lorr. 10, fol. 19, 236f., 509-512, und 624-627.

${ }^{250}$ AMAE, CP Lorraine 10, fol. $178 f$.

${ }^{231}$ AMAE, CP Lorraine 9, fol. 334f.

${ }^{252}$ Ibid. fol. 367-375. 
Aus Verdun kamen ebenfalls drängende Forderungen nach einer Änderung, insbesondere im Bereich der Gerichtsbarkeit. Der Bischof von Verdun, der nach der Kölner Episode von 1631 alle seine Einkünfte und Besitztümer zurückerhalten hatte, versuchte zunehmend, seine Gerichtsrechte gegenüber den königlichen Amtsträgern zu verteidigen ${ }^{253}$. In einem ausführlichen cahier des doléances von Bischof und Domkapitel wurde hierbei auch erneut die Souveränität aller Urteile der bischöflichen Gerichte betont ${ }^{254}$. Gleichzeitig forderten einige Stimmen in der Stadt die Anerkennung des Appellationsweges vor dem Pariser Parlament ${ }^{255}$. Auch das Domkapitel erneuerte seine Bestrebungen, den conseil du roi oder das Parlament von Paris als Berufungsgericht durchzuset$z^{2}{ }^{256}$. Diese Forderungen sollten vor allem die königlichen Instanzen vor Ort ausschalten, was auch eine anonyme Denkschrift von königstreuer Seite deutlich machte: In ihr wurde deshalb eine chambre souveraine in Verdun selbst als Lösung vorgeschlagen ${ }^{257}$. Eine solche compagnie souveraine hatte schon 1625 auch der Verduner Adel gefordert ${ }^{258}$. Noch deutlicher wurde eine anonyme Denkschrift aus der gleichen Zeit, die ausdrücklich ein Parlament forderte $^{259}$.

Verdun stand zudem wegen des Prozesses gegen seinen ehemaligen Gouverneur, den Marschall Louis de Marillac, der dort geführt wurde, im Zentrum der öffentlichen Aufmerksamkeit. Marillac wurde nach mehreren Monaten Gefangenschaft nach Verdun überführt und traf dort im Juli 1631 ein. Die Straftaten, die man ihm vorwarf, bezogen sich vor allem auf seine Amtsführung in Verdun: Er habe Gelder unterschlagen, lautete eine Hauptanklage. Tatsächlich ging es jedoch Richelieu vor allem darum, den Einfluß seiner Familie und der von ihr verkörperten außenpolitischen Vorstellung der dévôts zurückzudrängen $^{260}$. Die Kommission, die mit dem Prozeß gegen Marillac beauftragt war, ist vor allem wegen der beteiligten Personen eine nähere Betrachtung wert. Die Richter, meist Mitglieder des Parlement de Bourgogne in Dijon, sollten zum Großteil nämlich bei der Errichtung des Parlaments in Metz noch einmal eine wichtige Rolle spielen. Unter ihnen befanden sich auch der spätere erste Präsident des Metzer Parlaments, Claude-Antoine de Bretagne, und der

${ }^{253}$ Ibid. fol. 338-341.

${ }^{254}$ A.D. Meuse 11 F 7, 2.

${ }^{255}$ Auf diese Forderungen reagiert eine Denkschrift von königlicher Seite: AMAE, CP Lorraine 9, fol. 342.

${ }^{256}$ AMAE, CP Lorraine 10, fol. 32.

${ }^{257}$ AMAE, CP Lorraine 9, fol. 342.

${ }^{258}$ BnF, N.a.fr. 7101, fol. 1-14.

${ }^{259}$ AMAE, CP Lorraine 9, fol. 387-396.

${ }^{260}$ Vgl. dazu die Ausführungen von MouSNIER, L'homme rouge, S. 376-390. Eine gute Zusammenfassung findet sich bei BERCÉ, Naissance dramatique, S. 136. 
aus der Kommission von 1625 bekannte Staatsrat Cardin Le Bret ${ }^{261}$. Ursprünglich war es auch Le Bret, der für seine Arbeit mit dem Amt des ersten Präsidenten am Metzer Parlament belohnt werden sollte ${ }^{262}$. Ganz in Richelieus Sinne wurde der ehemalige Gouverneur von Verdun zum Tode verurteilt. Marillac wurde im Mai 1632 in Paris hingerichtet. In Verdun hatte man die Richterkommission nicht gerade mit offenen Armen aufgenommen: Das übliche Geschenk für hohen Besuch, die berühmten Zuckerbonbons (dragées) der Stadt, wurde ihr »aus Kostengründen « vorenthalten ${ }^{263}$.

Die Gefahr, die vom Herzog von Lothringen und dessen Verbindungen zu Spanien, dem Kaiser, aber auch zur innerfranzösischen Opposition ausging, war auch nach dem Vertrag vom Januar 1632, in dem Charles IV im Prinzip alle außenpolitische Eigenständigkeit aufgegeben hatte, nicht gebannt ${ }^{264}$. Bezeichnend war, daß Herzog Charles IV kurz vor Abschluß des Vertrages heimlich der bereits erwähnten Heirat seiner Schwester Marguerite mit dem aufrührerischen Bruder des Königs, Gaston d'Orléans, beigewohnt hatte. Diese Heirat lief den Interessen des Königs direkt entgegen ${ }^{265}$. Vor diesem Hintergrund schien es geboten, die jurisdiktionellen und verwaltungsrechtlichen Kontrollmöglichkeiten der Krone in den Trois-Évêchés auszuweiten. Herzog Charles IV war, wenn auch ungenügend, zunächst einmal durch den Vertrag von Vic gebunden. Das Hochstift Metz war durch eine königliche Garnison besetzt und die drängende Notwendigkeit einer verstärkten königlichen Einflußnahme auf die Justiz schien durch zahlreiche Denkschriften hinreichend bewiesen. Welches Mittel hierfür am geeignetsten sei, darüber war man sich schon seit längerer Zeit einig: Als Ludwig XIII. am 9. Februar im Begriff war, Metz zu verlassen, ließ er verkünden, bald werde man hier ein Parlament errichten ${ }^{266}$.

${ }^{261} \mathrm{Zu}$ Le Brets Beteiligung vgl. PICOT, Cardin Le Bret, S. 44. Zu Bretagne vgl. MiCHEL, Biographie, S. 57.

${ }^{262}$ PICOT, Cardin Le Bret, S. 39f. und 44.

${ }^{263}$ Petitot-Bellavène, Deux siècles, S. 292.

${ }^{264} \mathrm{Zu}$ Herzog Charles IV, seinen Beziehungen zu Habsburg und dem Vertrag von Vic: BABEL, Zwischen Habsburg, insbes. S. 141f.

${ }^{265} \mathrm{Zu}$ Gaston d'Orléans in Lothringen vgl. CABOURdiN, Histoire de la Lorraine, Bd. 3,1, S. 183-188.

${ }^{266}$ LE MOIGNE, Histoire de Metz, S. 238. 


\section{Resümee}

Betrachtet man die Ereignisse nach 1552, fällt zunächst auf, daß die Besetzung von Metz, Toul und Verdun völlig ohne Widerstand erfolgte. Die schwierige innere Situation aller drei Städte begünstigte eine prokönigliche Stimmung: In Metz beispielsweise machte der konfessionelle Gegensatz im Rat die Protestanten zu Verbündeten des Königs, während in Verdun der Überdruß breiter Bevölkerungsgruppen an der patrizischen Alleinherrschaft und, genau wie in Toul, der Ärger über hohe Steuerforderungen aus dem Reich die Stimmung zugunsten des französischen Königs gewendet hatten. Wie erschöpft die patrizischen Magistrate waren, zeigt sich auch daran, daß durch die Besetzung in Metz und Verdun ein regelrechtes Machtvakuum entstanden zu sein scheint, in das zunächst die Bischöfe hineinstießen, die somit wieder die Kontrolle über die Stadtregierung erlangen konnten. Hierzu paßt die Annahme einer Krise des städtischen Selbstverständnisses in den Jahrzehnten vor 1552, die Martial Gantelet am Beispiel von Metz konstatiert hat. Seine Analyse der berühmten Chronik des Philippe de Vigneulles macht deutlich, daß Selbstbewußtsein und Zusammengehörigkeitsgefühl von Bürgergemeinde und Magistrat schon lange vor der Besetzung durch königliche Truppen deutliche Risse zeigten ${ }^{267}$.

Von französischer Seite kam es nach 1552 zunächst zu keinerlei Eingriffen, die utber die Einsetzung von Garnisonen in allen drei Städten hinausgingen. Bald jedoch wurde deutlich, daß es, vor allem in Metz, wo die größte Garnison stationiert war, einer Person bedurfte, die auftretende Konflikte zwischen Soldaten und der Bevölkerung schlichten konnte. Das dafür geschaffene Amt des président vereinte zwei verschiedene Traditionen. Zum einen knüpfte man damit an die Inspektionsreisen der maîtres des requêtes, die sogenannten chevauchées, an, was auch an der Tatsache deutlich wird, daß keine neue Institution geschaffen wurde, sondern eine Einzelperson mit dem Rechtstitel des président und einem bestimmten Auftrag entsendet wurde.

Zum anderen wurde aber bereits in der Bezeichnung président die Anknüpfung an die 1552 geschaffenen Présidial-Gerichte deutlich. Diese führten die Aufsicht über die prévôts, also die Militärgerichte, waren aber gleichzeitig Berufungsinstanz in Zivilsachen oberhalb der bailliages. Hier wird also bereits der Anspruch auf einen Vorrang vor den städtischen Gerichten und mögliche Kompetenzen als Berufungsinstanz für diese deutlich. Doch umzusetzen war dieser Anspruch zunächst nicht. Auch die weiteren Gesandtschaften sowie die nach und nach in allen drei Städten eingesetzten procureurs blieben auf sich

${ }^{267}$ GANTELET, Entre France et Empire, in: Revue historique 125 (2001) S. 5-45. 
gestellt und konnten so einen echten Anspruch auf Gerichtsbarkeit schon physisch gar nicht durchsetzen.

Die Gouverneure als Militärbefehlshaber vor Ort entwickelten zudem gewisse Verselbständigungstendenzen, indem sie eigene Interessen vor die ihres Königs stellten. Ein Beispiel hierfür ist die Tatsache, daß sie zunehmend Familienmitglieder in die zahlreichen Kirchenämter der Trois-Évêchés bringen wollten. So etwa der Touler Gouverneur-Vertreter Jacques Ligniville de Vannes, der seinen Neffen zum Bischof machen wollte. Die Gouverneure von Verdun und Metz, Marillac und Épernon, spielten zudem in der Innenpolitik des Königreiches eine wichtige Rolle und hatten im Falle eines Konflikts mit dem König in ihren Gouvernements am Rande Frankreichs jederzeit ein Rückzugs- oder sogar ein Aufmarschgebiet. Ein Gegengewicht zu ihrer Position zu schaffen, war deshalb zunächst eines der wichtigsten Ziele französischer Rechtspolitik.

Erfolgreich war die Politik des Königs in den Trois-Évêchés immer dann, wenn sich seine Interessen mit denen anderer Kräfte in Lothringen deckten: Dies war bei den bereits angesprochenen Ruickeroberungen der stadtherrlichen Gewalt durch die Bischöfe in Metz und Verdun der Fall, wo sich die bischöflichen und die königlichen Interessen ergänzten. Aber auch bei den Bischofswahlen der folgenden Jahre gelang es schon durch die bestehenden verwandtschaftlichen Beziehungen, die königlichen mit den herzoglich-lothringischen Interessen gegen die Interessen der Domkapitel und möglicherweise auch Roms zu verbinden.

Dies sollte jedoch in dem Moment obsolet werden, als mit der Bildung der katholischen Liga, die aufs engste mit dem lothringischen Herzogshaus verbunden war, ein offener Bruch zwischen dem französischen König und dem Herzog zutage trat. In den Religionskriegen waren Toul und Verdun faktisch über Jahre hinweg jeder königlichen Kontrolle entzogen, und der Herzog von Lothringen nahm die zuvor königliche Position des »Protektors« ein.

Wie stark die jeweiligen Ansprüche innerhalb der Städte für Konflikte instrumentalisiert werden konnten, zeigt die Auseinandersetzung um die Rechtsprechung im Bezirk des cloitre von Verdun, in dem sich die Angehörigen des Domkapitels durch Anbringung königlicher Wappen an ihren Häusern der städtischen Justiz zu entziehen suchten, den Konflikt aber schließlich vor dem Reichskammergericht entscheiden ließen.

Ähnlich ambivalent war die Situation des président in Metz: Solange er und der Magistrat das gleiche Ziel verfolgten, nämlich die Berufungen vor dem Reichskammergericht abzuschaffen, konnte er relativ problemlos arbeiten. Als er jedoch immer weitere Kompetenzen beanspruchte und nicht mehr als ein Teilnehmer an den Sitzungen der städtischen Gerichte, sondern als Vorsitzender dieser Institutionen agieren wollte, kam es zum Konflikt. 
Bemerkenswert ist hierbei, wie deutlich nicht nur in der Stadt Metz, sondern auch in den Städten, Hochstiften und Domkapiteln von Toul und Verdun die jeweiligen Interessen in Bittschriften und Beschwerdeheften artikuliert wurden. Von einem gewaltsamen Widerstand, etwa gegen die Maßnahmen des président oder gegen den geforderten Treueid, ist hingegen kein Hinweis überliefert. Dies mag daran liegen, daß die schriftlichen Äußerungen der Bewohner, oder besser gesagt, der Eliten der einzelnen Städte und Territorien, keineswegs auf taube Ohren stießen. Immer wieder wurde den Anliegen stattgegeben oder eine Anordnung angeschwächt bzw. nicht auf ihrer Umsetzung bestanden. Lediglich das Festhalten an einer königlichen Zuständigkeit bei bestimmten Verfahren zeigt, wie sich anhand der Theorie der cas royaux ein bestimmter Herrschaftsanspruch verfestigt hatte.

Ein anderer Grund für das geringe $\mathrm{Ma} \beta$ an echtem »Widerstand « trotz der großen Zahl an Beschwerden und Bittschriften ist, daß die königliche Politik keineswegs grundsätzlich abgelehnt wurde. Dies zeigt das Bestreben vieler Bewohner, sich in der Entscheidung von Rechtsfragen an die Pariser Gerichte zu wenden. Denn auch wenn vereinzelt weiterhin an den Berufungen vor dem Reichskammergericht festgehalten werden sollte, war es nicht die Anhänglichkeit der Bevölkerung zum Reich, die dafür sorgte, daß sich der président auch nach 1600 trotz vieler königlicher Anordnungen zur Kompetenzausweitung nicht durchsetzen konnte. Dies lag vielmehr vor allem daran, daß die Kläger die Pariser Gerichte vorzogen. Zunächst wurde vor allem vor dem conseil du roi geklagt. Als dieser zunehmend an den président zurückverwies, wandte man sich an das Pariser Parlament. Hier wird deutlich, daß der König und auch seine Gerichte prinzipiell durchaus anerkannt wurden. Das Bestreben der Kläger, ein Urteil von einem möglichst renommierten Gericht zu erhalten, deckte sich in gewisser Weise sogar mit den Interessen der städtischen Magistrate und der Bischöfe. Sie strebten zwar grundsätzlich die Souveränität (d.h. keine Berufungen an Gerichte anderer Autoritäten) ihrer Urteile an, aber wo sich dies nicht durchsetzen ließ, zogen sie eine weiter entfernte Berufungsinstanz - ob in Paris oder Speyer - einem Gericht vor Ort vor, weil dies die Zahl der Berufungen und damit auch das Ausmaß $B$ der Kontrolle geringer hielt.

Die Bindung zum König wurde noch gestärkt durch geschickt inszenierte symbolische Akte wie die Treueide und die feierlichen Einzüge des Königs in die Städte ${ }^{268}$, bei denen sich virtuos des gesamten Instrumentariums der »Informationszeremonien « (M. Fogel) ${ }^{269}$ bedient wurde. Doch nimmt man

${ }^{268} \mathrm{Vgl}$. zu diesen symbolischen Akten Jens Ivo ENGELS, Königsbilder. Sprechen, Singen und Schreiben über den französischen König in der ersten Hälfte des achtzehnten Jahrhunderts, Bonn 2000 (Pariser Historische Studien, 52), und Michèle FoGEL, Les cérémonies de l'information dans la France du XVI' au milieu du XVIII' siècle, Paris 1989.

${ }^{269}$ FoGEL, Cérémonies, hier v.a. S. 11-19. 
daneben auch die alltägliche Tätigkeit der königlichen Vertreter vor Ort und der zahlreichen zu Einzelmissionen oder Kommissionen entsendeten Juristen in den Blick, zeigt sich, daß nicht nur, wie Fogel dies herausgearbeitet hat, die Bevölkerung »informiert« wurde, sondern daß sich der König und sein Umfeld auch selbst über das Gerichtswesen, die politische Situation sowie die historischen und geographischen Verhältnisse in den neugewonnenen Gebiete informierten, bzw. informiert wurden ${ }^{270}$. Schon weil sie in der direkten Verwaltung kaum eingreifen konnten, berichten die einzelnen Amtsträger eifrig nach Paris. Und gerade in diesen Informationen verdichteten sich immer mehr Stimmen zu einem Chor, der eine »richtige « königliche Institution vor Ort, eine chambre souveraine oder ein Parlament forderte.

${ }^{270}$ Ähnliche Beobachtungen bei der Untersuchung des geographischen Raumes bei Daniel NORDMAN, Frontières de France. De l'espace au territoire XVI ${ }^{e}-X^{e} X^{e}$ siècle, Paris 1998, v.a. S. 123-282, und SAHLINS, Boundaries, S. 61-102. 
